\title{
HREELS, TPD and XPS study of the interaction of water with the $\alpha-\mathrm{Cr}_{2} \mathrm{O}_{3}(001)$ surface
}

\author{
Michael A. Henderson *, Scott A. Chambers \\ Environmental Molecular Sciences Laboratory, Pacific Northwest National Laboratory, P.O. Box 999, MS K8-93, \\ Richland, WA 99352, USA
}

Received 1 October 1999; accepted for publication 7 December 1999

\begin{abstract}
The interaction of water with the (001) surface of $\alpha-\mathrm{Cr}_{2} \mathrm{O}_{3}$ was examined with temperature programmed desorption (TPD), high resolution electron energy-loss spectroscopy (HREELS) and X-ray photoelectron spectroscopy (XPS). Two $\alpha-\mathrm{Cr}_{2} \mathrm{O}_{3}(001)$ surfaces were examined, both of which were grown on $\alpha-\mathrm{Al}_{2} \mathrm{O}_{3}(001)$ substrates using oxygen plasma-assisted molecular beam epitaxy (MBE). The two surfaces differed in that one was grown with $\alpha-\mathrm{Fe}_{2} \mathrm{O}_{3}$ interlayers whereas the other was grown directly on $\alpha-\mathrm{Al}_{2} \mathrm{O}_{3}(001)$. The in-plane lattice spacing of the $\alpha-\mathrm{Cr}_{2} \mathrm{O}_{3}(001)$ surface on $\alpha-\mathrm{Fe}_{2} \mathrm{O}_{3} / \alpha-\mathrm{Al}_{2} \mathrm{O}_{3}(001)$ was $2 \%$ expansively strained relative to the unstrained $\alpha-\mathrm{Cr}_{2} \mathrm{O}_{3}(001)$ surface grown directly on $\alpha-\mathrm{Al}_{2} \mathrm{O}_{3}(001)$. Both the strained and unstrained surfaces exhibited similar water TPD behavior, with the possible exception that the desorption states of water on the strained surface were shifted slightly to lower temperatures relative to those on the unstrained surface. Water adsorbs on $\alpha-\mathrm{Cr}_{2} \mathrm{O}_{3}(001)$ in both molecular and dissociative states, with the former desorbing in TPD at $295 \mathrm{~K}$ and the latter at $345 \mathrm{~K}$. TPD uptake measurements and XPS data suggest that each surface $\mathrm{Cr}^{3+}$ atom has the capacity to bind two water molecules, one in a molecular state and one in a dissociative state. Water in the dissociative state is comprised of two distinct OH groups based on HREELS, one of which is a terminal group with a $v(\mathrm{OH})$ mode at $3600 \mathrm{~cm}^{-1}$ and the other of which is presumably a bridging group with a $v(\mathrm{OH})$ mode at $2885 \mathrm{~cm}^{-1}$. These losses shift to 2645 and $2120 \mathrm{~cm}^{-1}$ with $\mathrm{D}_{2} \mathrm{O}$ adsorption. The low loss energy for the bridging $\mathrm{OH} / \mathrm{OD}$ group indicates its involvement in a very strong hydrogen-bonded interaction with another species, presumably the oxygen atom of the terminal $\mathrm{OH}$ group. This pairing behavior is likely responsible for the first-order desorption kinetics observed for the recombinative desorption state at $345 \mathrm{~K}$. The hydrogen-bonding interaction is unusually strong, as exemplified by the very low $v(\mathrm{OH})$ frequency for the bridging $\mathrm{OH}$ group. Studies on the oxygen pre-exposed surface indicate that oxygen atoms, formed by $\mathrm{O}_{2}$ dissociation, block the $\mathrm{H}_{2} \mathrm{O}$ dissociative channel but do not block the molecular adsorption channel. (C) 2000 Elsevier Science B.V. All rights reserved.
\end{abstract}

Keywords: Chromium; Electron energy loss spectroscopy (EELS); Single crystal epitaxy; Surface chemical reaction; Thermal desorption spectroscopy; Vibrations of adsorbed molecules; Water; X-ray photoelectron spectroscopy

\section{Introduction}

The molecular-level interactions of water with oxide surfaces are of great fundamental importance

* Corresponding author. Fax: +1-509-376-5106.

E-mail address: ma.henderson@pnl.gov (M.A. Henderson) in understanding many chemical, geochemical and material science phenomena. Most oxide surfaces exposed to the ambient are decorated with a variety of molecularly and dissociatively adsorbed forms of water. These various species influence and alter the chemical reactivity of oxide surfaces in different ways. Yet the surface structural proper- 
ties of the oxide that influence water chemistry are not well understood. Studies on single crystals greatly facilitate the potential for understanding the relationship between surface structure and surface reactivity.

The basal plane [also referred to as the (001) or (0001) plane] of corundum materials, such as $\alpha-\mathrm{Al}_{2} \mathrm{O}_{3}, \alpha-\mathrm{Cr}_{2} \mathrm{O}_{3}$ and $\alpha-\mathrm{Fe}_{2} \mathrm{O}_{3}$, offers the unique structural environment of highly coordinatively unsaturated cation sites at a reasonably high surface density and with a fairly well-understood surface structure. The outermost layer of these surfaces is comprised of a layer of cations residing on a sheet of oxygen anions [1-12]. The surface cation sites are three-fold coordinated, whereas cations in the bulk are six-fold coordinated. This undercoordination results in the surface cations relaxing inward toward the outermost sheet of oxygen anions in order to lower the surface free energy, whereas the relaxation is somewhat lifted by a chemisorbed layer. The surface coverage of these three-coordinated cations is one third of that of the anions in the underlying oxygen sheet, resulting in surface charge neutrality with the number of metal-derived dangling bonds being equivalent to the number of oxygen-derived dangling bonds. The ideal $\alpha-\mathrm{Cr}_{2} \mathrm{O}_{3}(001)$ surface termination is illustrated in Fig. 1. Although this is the general structure adopted by many studies, at

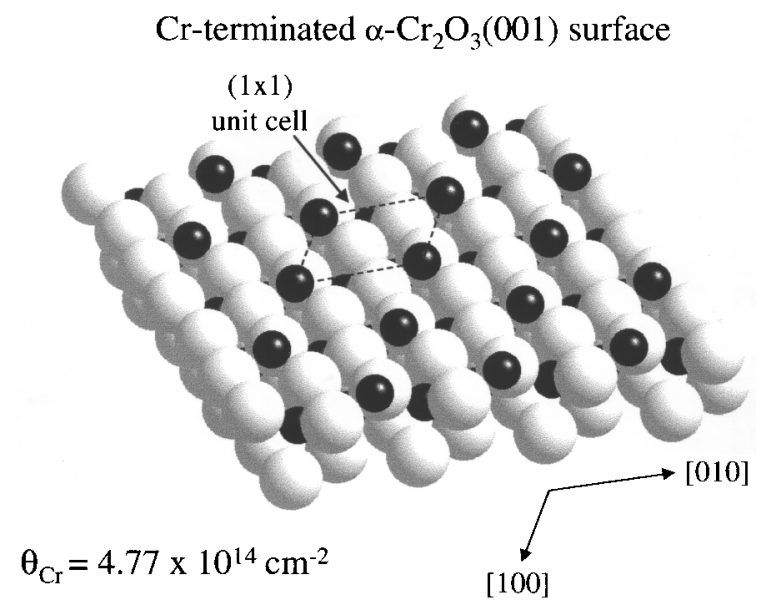

Fig. 1. Schematic model of the Cr-terminated $\alpha-\mathrm{Cr}_{2} \mathrm{O}_{3}(001)$ surface. The small black circles are $\mathrm{Cr}^{3+}$ cations and the large white circles are $\mathrm{O}^{2-}$ anions. least one study has recently proposed that the cations in the surface are disordered at room temperature, and that interstitials may exist between the first two anion sheets [12].

The interaction of water with the (001) plane of $\alpha-\mathrm{Cr}_{2} \mathrm{O}_{3}$ has been examined in this study. Previous experimental work on the interaction of water with the $\alpha-\mathrm{Cr}_{2} \mathrm{O}_{3}(001)$ surface has suggested that water dissociation occurs only at defect sites based on photoemission results [13]. This conclusion is partially corroborated by semi-empirical embedded cluster calculations by Bredow, which suggest that molecular adsorption is favored over dissociative adsorption on the Cr-terminated surface [1]. Results presented in this study, however, show that the three-fold coordinated $\mathrm{Cr}^{3+}$ sites on the $\alpha-\mathrm{Cr}_{2} \mathrm{O}_{3}(001)$ surface not only dissociate water under ultrahigh vacuum (UHV) conditions, but also have the capacity to bind both a water molecule and a hydroxyl group, resulting in a total water monolayer coverage of twice the surface density of cation sites. The hydroxyl channel is blocked, however, by preadsorbed oxygen.

\section{Experimental}

The $\alpha-\mathrm{Cr}_{2} \mathrm{O}_{3}(001)$ surfaces used in this study were grown on $\alpha-\mathrm{Al}_{2} \mathrm{O}_{3}(001)$ substrates using molecular beam epitaxy (MBE). The films were grown at a substrate temperature of about $775 \mathrm{~K}$ using growth rates between 0.03 and $0.1 \AA / \mathrm{s}$ in an oxygen plasma (for additional details see Ref. [14]). Two different films are discussed in this study, both of which were characterized in the MBE system using low energy electron diffraction (LEED), reflection high-energy electron diffraction (RHEED), X-ray photoelectron spectroscopy (XPS) and X-ray photoelectron diffraction (XPD). RHEED [14] and XPD [15] results indicate that both films are corundum in structure (hence the ' $\alpha$ ' designation). The first film consisted of alternating layers of $\alpha-\mathrm{Cr}_{2} \mathrm{O}_{3}$ and $\alpha-\mathrm{Fe}_{2} \mathrm{O}_{3}$ of variable thickness terminated with about $200 \AA$ of $\alpha-\mathrm{Cr}_{2} \mathrm{O}_{3}$. The $\alpha-\mathrm{Cr}_{2} \mathrm{O}_{3}$ film on $\alpha-\mathrm{Fe}_{2} \mathrm{O}_{3}$ maintains the in-plane lattice spacing of $\alpha-\mathrm{Fe}_{2} \mathrm{O}_{3}(001)$, which is about $2 \%$ expanded relative to the spacing in the natural $\alpha-\mathrm{Cr}_{2} \mathrm{O}_{3}(001)$ surface. The surface of 
this film will hereafter be referred to as the strained $\alpha-\mathrm{Cr}_{2} \mathrm{O}_{3}(001)$ surface. The second film consisted of about $500 \AA$ of $\alpha-\mathrm{Cr}_{2} \mathrm{O}_{3}$ grown directly on $\alpha-\mathrm{Al}_{2} \mathrm{O}_{3}(001)$. RHEED results indicate that the surface of this $\alpha-\mathrm{Cr}_{2} \mathrm{O}_{3}$ film on $\alpha-\mathrm{Al}_{2} \mathrm{O}_{3}(001)$ adopts the bulk-like in-plane spacing of $\alpha-\mathrm{Cr}_{2} \mathrm{O}_{3}(001)$ [14]. The surface of this film will hereafter be referred to as the unstrained $\alpha-\mathrm{Cr}_{2} \mathrm{O}_{3}(001)$ surface. The LEED pattern of the strained $\alpha-\mathrm{Cr}_{2} \mathrm{O}_{3}(001)$ surface showed the typical hexagonal pattern observed in other studies [1618]. The spots were very sharp, and the background was low. The LEED pattern from the unstrained surface possessed broader spots with a higher background. As will be discussed below, this was due to substantial charging of unstrained surface in the LEED beam. Charging in the X-ray source was alleviated by using a low energy electron flood gun.

XPS of the strained film showed only $\mathrm{Cr}$ in the formal $3+$ oxidation state with the expected multiplet splitting observed in the $\mathrm{Cr} 2 \mathrm{p}$ features [14]. The splitting does not change irrespective of whether grazing or normal angle detection is employed, suggesting that the $\mathrm{Cr}$ cations in the surface and bulk have the same oxidation state. This same behavior was observed by Dillmann et al. for thin $\mathrm{Cr}_{2} \mathrm{O}_{3}(0001)$ films grown on $\mathrm{Cr}(110)$ [19]. Splitting in the $\mathrm{Cr} 2 \mathrm{p}_{3 / 2}$ spectrum of thin $\mathrm{Cr}_{2} \mathrm{O}_{3}(0001)$ films grown on $\mathrm{Cr}(110)$ was originally assigned to the simultaneous presence of $\mathrm{Cr}^{2+}$ and $\mathrm{Cr}^{3+}$ at the surface by this group [16], but was later re-interpreted to multiplet splitting $[19,20]$. However, recently this group has used ab initio cluster calculations to suggest the surface $\mathrm{Cr}$ cations are in the $2+$ oxidation state [21]. Although an assignment to $\mathrm{Cr}^{3+}$ is used here based on the similarity of the bulk-sensitive and surface-sensitive XPS measurements, this issue is not a focus of this paper and will not be discussed further.

The films were transferred through air to a second UHV system for studies with temperature programmed desorption (TPD), high resolution electron energy-loss spectroscopy (HREELS), Auger electron spectroscopy (AES) and static secondary ion mass spectrometry (SSIMS). The samples were mounted in the second UHV cham- ber using a method described previously [22], that permits heating to $1000 \mathrm{~K}$, and cooled to below $120 \mathrm{~K}$. Briefly, this method involves sandwiching a thin $\mathrm{Au}$ foil between the back face of the crystal and the polished surface of a Ta plate, with the crystal held in place by mechanical force applied using $\mathrm{W}$ clips. After transfer and bakeout, the film surfaces were covered with a monolayer (or more) of carbonaceous deposits, along with some alkali ions and assorted other trace contaminants. These impurities were easily removed by mild sputtering with $500 \mathrm{~V} \mathrm{Ar}^{+}$and by annealing in UHV. The strained surface showed little or no effect of charging during sputtering at $300 \mathrm{~K}$, but the unstrained surface required simultaneous exposure to $20 \mathrm{eV}$ electrons from a flood gun in order for the sample not to charge during sputtering. Fig. 2 shows the AES spectrum (using a $3 \mathrm{keV}$ electron beam) from the strained $\alpha-\mathrm{Cr}_{2} \mathrm{O}_{3}(001)$ surface after sputtering and annealing at $850 \mathrm{~K}$ in UHV. Aside from the small Ar AES feature at $214 \mathrm{eV}$, all other features

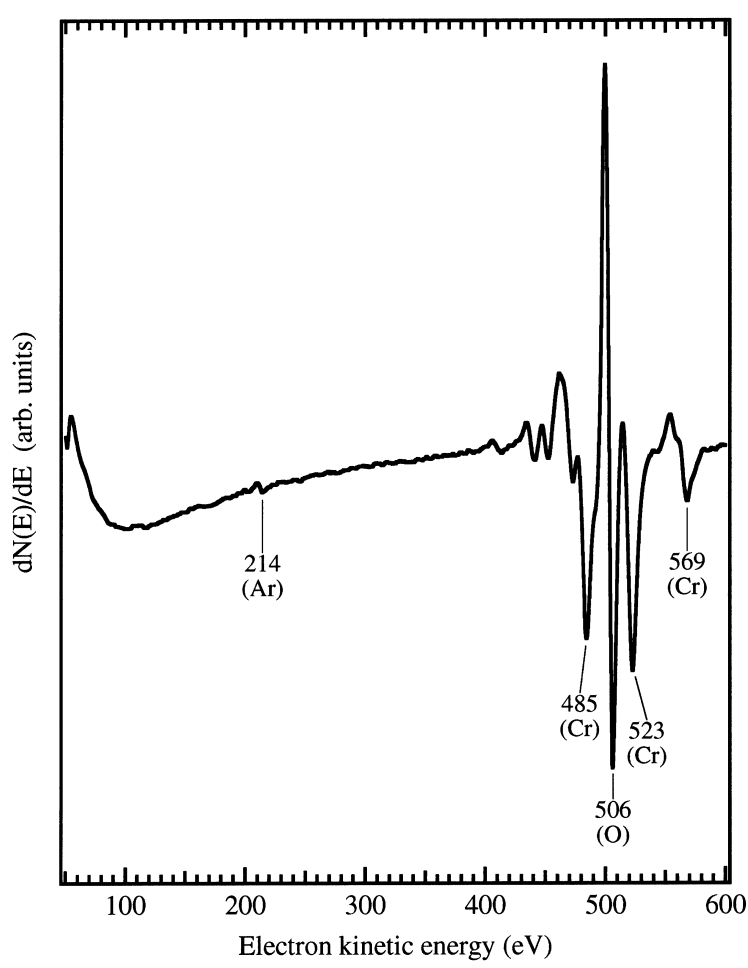

Fig. 2. AES spectrum of the clean strained $\alpha-\mathrm{Cr}_{2} \mathrm{O}_{3}(001)$ surface. 
observed are from $\mathrm{Cr}$ or $\mathrm{O}$. This AES spectrum resembled that published previously by Fukuda and Ignatiev from a polycrystalline $\alpha-\mathrm{Cr}_{2} \mathrm{O}_{3}$ film on $\mathrm{Cr}$ metal [23]. AES of the unstrained surface was not possible due to sample charging.

The diffusion of $\mathrm{Fe}$ and/or $\mathrm{Al}$ from the underlying films and/or substrate during high temperature annealing was of concern, so the levels of $\mathrm{Fe}^{+}$and $\mathrm{Al}^{+}$were monitored over time using SSIMS. The SSIMS $\mathrm{Fe}^{+}$and $\mathrm{Al}^{+}$signals, compared with the total $\mathrm{Cr}^{+}$yield from all its isotopes, were $1-2 \%$ and $<1 \%$ (respectively) for the clean strained surface, and $0 \%$ and 6-7\% (respectively) for the clean unstrained surface. These impurity levels are reasonable given that the strained film was grown on an $\alpha-\mathrm{Fe}_{2} \mathrm{O}_{3}$ film, and the unstrained film was grown directly on $\alpha-\mathrm{Al}_{2} \mathrm{O}_{3}(001)$.

High purity $\mathrm{H}_{2} \mathrm{O}$ and $\mathrm{D}_{2} \mathrm{O}$ were obtained from Aldrich, and were further purified by several freepump-thaw cycles. The gasline used in dosing water was acclimate to each gas prior to use. Water was dosed through a $1 / 4^{\prime \prime}$ OD stainless steel tube using a calibrated pinhole aperture doser. Typical exposures involved placing the crystal within $1 \mathrm{~mm}$ of the front of the tube followed by admitting approximately 100-200 mTorr of $\mathrm{H}_{2} \mathrm{O}$ to the high pressure side of the pinhole. Exposures were then culminated by evacuating the high pressure side of the pinhole and waiting for about $60 \mathrm{~s}$ to capture residual water molecules emerging down the tube from the pinhole. The exact surface area of the sample exposed to the water beam is not accurately known. As discussed in the text, the profile of the dosed 'spot' on the sample is likely domed, extending beyond the surface area defined by the inner diameter of the dosing tube. Therefore, the actual exposures on the sample are smaller than those estimated using an exposed area based on the doser tube's cross-sectional area, and may be somewhat non-uniform due to the doming effect. All TPD measurements were performed by dosing water with the sample at $120 \mathrm{~K}$ followed by heating at a rate of $2 \mathrm{~K} / \mathrm{s}$. Separate water experiments were conducted in the MBE system in order to measure the $\mathrm{O} 1 \mathrm{~s}$ core-level spectra. Water doses of $300 \mathrm{~s}$ at a partial pressure of $5 \times 10^{-8}$ Torr were applied to the strained surface at sample temperatures of 250 and $300 \mathrm{~K}$.
The unstrained $\alpha-\mathrm{Cr}_{2} \mathrm{O}_{3}(001)$ film was susceptible to charging in the charged particle beams of LEED, HREELS, SSIMS and AES. As a result, HREELS experiments were performed only on the strained $\alpha-\mathrm{Cr}_{2} \mathrm{O}_{3}(001)$ surface, and only in the specular direction using a beam energy of $13.8 \mathrm{eV}$. Lower beam energies resulted in charging of this film, whereas higher beam energies were less sensitive to the dipole scattered losses of adsorbed water. The somewhat limited semiconducting behavior of the strained film was likely due to carrier states in the underlying $\alpha-\mathrm{Fe}_{2} \mathrm{O}_{3}(001)$ film, which was in contact with the $\mathrm{W}$ clips used to hold the substrate in place. Dosing and analysis temperatures for the HREELS experiments are mentioned in the text.

\section{Results and discussion}

\subsection{Interaction of water with the $2 \%$ strained $\alpha-\mathrm{Cr}_{2} \mathrm{O}_{3}(001)$ surface}

\subsubsection{TPD results}

Fig. 3 shows $\mathrm{H}_{2} \mathrm{O}(m / e=18)$ TPD spectra as a function of exposure from $\mathrm{H}_{2} \mathrm{O}$ adsorbed at $120 \mathrm{~K}$ on the strained $\alpha-\mathrm{Cr}_{2} \mathrm{O}_{3}(001)$ surface. At low exposures, a single $\mathrm{H}_{2} \mathrm{O}$ TPD state is observed at $345 \mathrm{~K}$ that does not shift with increasing exposure. This peak saturates at an $\mathrm{H}_{2} \mathrm{O}$ exposure between 0.9 and $1.0 \times 10^{15}$ molecules $/ \mathrm{cm}^{2}$. A second $\mathrm{H}_{2} \mathrm{O}$ TPD state grows in at about $295 \mathrm{~K}$ in this same exposure regime. This second $\mathrm{H}_{2} \mathrm{O}$ TPD peak is not saturated for exposures below $1.4 \times$ $10^{15}$ molecules $/ \mathrm{cm}^{2}$. Additional $\mathrm{H}_{2} \mathrm{O}$ TPD states appear at 185 and $210 \mathrm{~K}$ for $\mathrm{H}_{2} \mathrm{O}$ exposures between 1.4 and $2.0 \times 10^{15}$ molecules $/ \mathrm{cm}^{2}$, whereas exposures above $2.0 \times 10^{15}$ molecules $/ \mathrm{cm}^{2}$ result in multilayer formation at $165 \mathrm{~K}$. The TPD states at 295 and $345 \mathrm{~K}$ can be assigned to chemisorbed forms of adsorbed water, presumably at $\mathrm{Cr}^{3+}$ cation sites, whereas the TPD states at 185 and $210 \mathrm{~K}$ can be assigned to physisorbed or hydrogenbonded forms of adsorbed water. The amount of water adsorbed in the 185 and $210 \mathrm{~K}$ TPD states prior to multilayer formation is only about $30 \%$ of that adsorbed above $250 \mathrm{~K}$, suggesting that the 


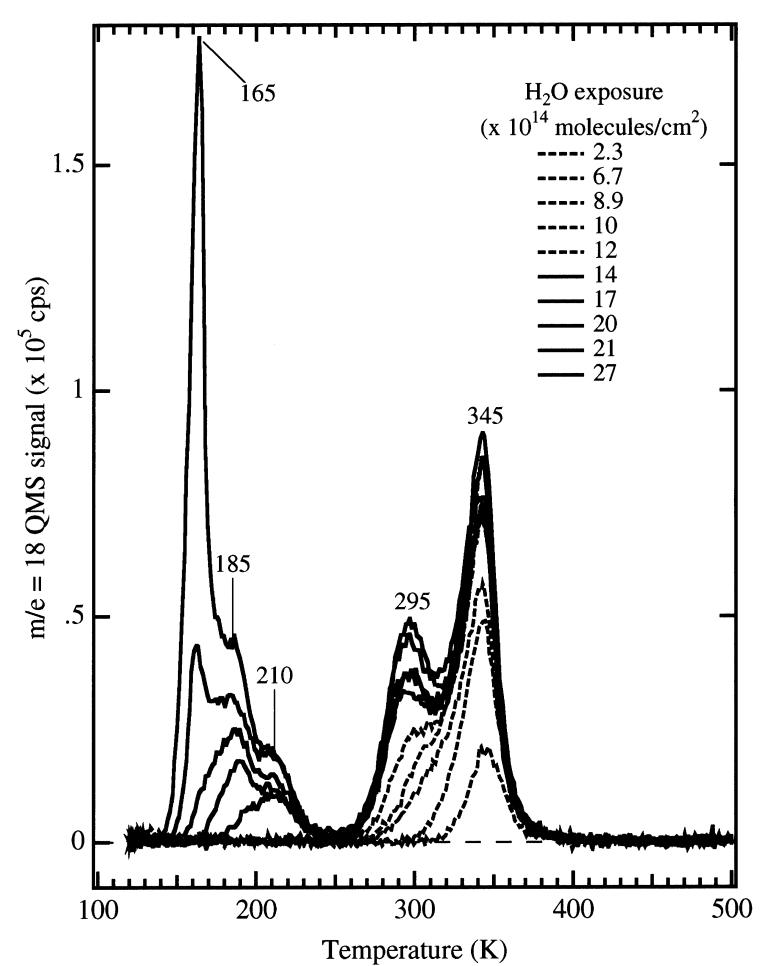

Fig. 3. TPD spectra of $\mathrm{H}_{2} \mathrm{O}(m / e=18)$ from various $\mathrm{H}_{2} \mathrm{O}$ exposures at $120 \mathrm{~K}$ on the strained $\alpha-\mathrm{Cr}_{2} \mathrm{O}_{3}(001)$ surface. The dashed and solid line traces correspond to exposures above and below $1.3 \times 10^{15}$ molecules $/ \mathrm{cm}^{2}$, respectively.

coverage of these physisorption/hydrogen bonding sites is limited by the chemisorbed layer.

The $345 \mathrm{~K}$ TPD peak was fit to coverageindependent first-order desorption kinetics for water exposures below that required for formation of the $295 \mathrm{~K}$ TPD peak. Adequate fits were obtained with an activation energy of $89 \mathrm{~kJ} / \mathrm{mol}$ and a prefactor of $7 \times 10^{12} \mathrm{~s}^{-1}$. The peak shapes and widths of the fits matched the data well for coverages between 3 and $7 \times 10^{14}$ molecules $/ \mathrm{cm}^{2}$. However, slight coverage dependencies were necessary in order to fit the data at lower coverages.

Fig. 4 shows $\mathrm{H}_{2} \mathrm{O}$ TPD peak area analysis of the data in Fig. 3 (with the inclusion of data that is not shown in Fig. 3 for the sake of clarity). The two lines in Fig. 4 are from the total $\mathrm{H}_{2} \mathrm{O}$ TPD peak area (filled circles) and the $\mathrm{H}_{2} \mathrm{O}$ TPD peak area above $250 \mathrm{~K}$ (hollow circles), both as a function of $\mathrm{H}_{2} \mathrm{O}$ exposure on the clean strained

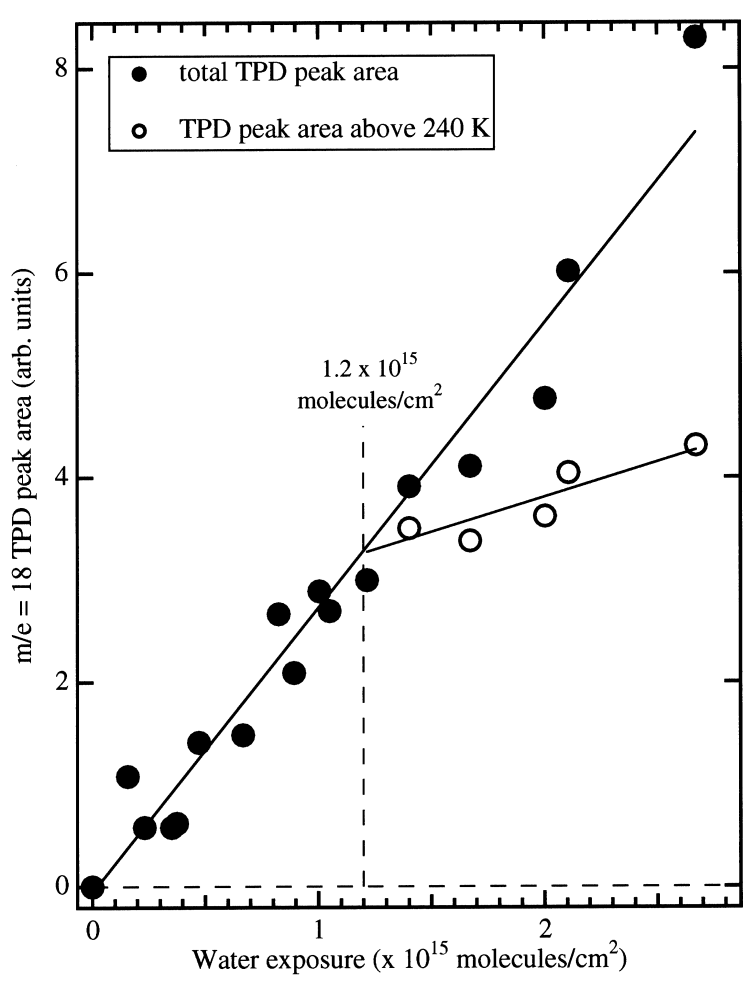

Fig. 4. Water TPD peak area data as a function of water exposure. The solid and hollow circles correspond to the total TPD peak area and the TPD peak area above $250 \mathrm{~K}$, respectively. Data points include, but are not restricted to, data shown in Fig. 3. Lines drawn through the data are from least-squares fits.

$\alpha-\mathrm{Cr}_{2} \mathrm{O}_{3}(001)$ surface. A first-order least-squares fit of the total TPD peak area data results in a line that intersects the origin. This indicates that within the detection limits of the system all adsorbed water molecules are recovered in TPD as water (that is, no irreversible decomposition occurs). The $250 \mathrm{~K}$ point was chosen as a delineation temperature between the high temperature and low temperature desorption states of $\mathrm{H}_{2} \mathrm{O}$. Water desorption above this temperature is primarily from species chemisorbed at cation sites. The intersection of the two lines occurs at an exposure of $1.2 \times 10^{15}$ molecules $/ \mathrm{cm}^{2}$, and corresponds to the coverage at which all cation sites are saturated (assuming unity sticking at $120 \mathrm{~K}$ ). The peak area data corresponding to monolayer saturation is not flat for exposures above $1.2 \times 10^{15}$ molecules $/ \mathrm{cm}^{2}$, as one would have expected. This effect has been 
observed in other water-oxide studies employing the collimated pinhole doser [22,24], and possibly indicates that the water beam emerging from the doser does not deposit a spot with a square-edged profile, but deposits a domed spot whose extremities exceed the inner diameter of the dosing tube (see experimental section). For this reason, the monolayer states on the fringes of the spot fill at a slower rate compared with those in the center of the spot. This effect has been discussed recently by Livingston et al. for the growth of water ice on $\mathrm{Ru}(001)$ [25]. As a consequence, the monolayer saturation coverage estimated by the intersection of the two least-squares traces in Fig. 4 represents a maximum because the surface area exposed to the beam is larger than the inside diameter of the tube (which is assumed to be the exposed surface area of the crystal).

The coverage of exposed $\mathrm{Cr}^{3+}$ cations on the ideal Cr-terminated $\alpha-\mathrm{Cr}_{2} \mathrm{O}_{3}(001)$ surface is $4.77 \times 10^{14} \mathrm{~cm}^{-2}$. However, when $\alpha-\mathrm{Cr}_{2} \mathrm{O}_{3}$ is grown on an $\alpha-\mathrm{Fe}_{2} \mathrm{O}_{3} / \alpha-\mathrm{Al}_{2} \mathrm{O}_{3}(001)$ film [14] (as discussed in the experimental section) it is lattice matched to the $\alpha-\mathrm{Fe}_{2} \mathrm{O}_{3}$ basal plane structure resulting in a surface $\mathrm{Cr}^{3+}$ coverage of $4.55 \times 10^{14} \mathrm{~cm}^{-2}$. Assuming the doming effect discussed above contributes a small error to the measured saturation water coverage from the data in Fig. 4, the saturation water coverage estimated in Fig. $4\left(1.2 \times 10^{15}\right.$ molecules $\left./ \mathrm{cm}^{2}\right)$ is roughly twice that of the surface $\mathrm{Cr}^{3+}$ cation site density, suggesting that two water molecules are adsorbed per surface $\mathrm{Cr}^{3+}$ cation site. In principle, multiple coordination should be possible since the exposed $\mathrm{Cr}^{3+}$ cations are lacking three 'ligands' in their coordination sphere. However, examples of coordination of multiple water molecules to a single metal cation have not, to our knowledge, been reported on a single crystal metal oxide surface.

Isotopic oxygen studies, such as those performed on $\mathrm{TiO}_{2}(110)$ and $\mathrm{TiO}_{2}(100)$ [26], and on $\alpha-\mathrm{Fe}_{2} \mathrm{O}_{3}(012)$ [24], were attempted on $\alpha-\mathrm{Cr}_{2} \mathrm{O}_{3}(001)$ in an effort to verify water dissociation. However, SSIMS results (not shown) indicate that the only ${ }^{18} \mathrm{O}$ incorporated into the surface while exposing $5 \times 10^{-7}$ Torr ${ }^{18} \mathrm{O}_{2}$ at 600 to $800 \mathrm{~K}$ was that due to adsorbed oxygen adatoms that capped each exposed $\mathrm{Cr}^{3+}$ cation site [19]. The
TPD spectrum of water adsorbed on the oxygen exposed surface is noticeably different from that for the clean surface, and will be discussed below. Although in concept the opposite exchange process $\left(\mathrm{H}_{2}{ }^{18} \mathrm{O}\right.$ adsorbed on the $\alpha-\mathrm{Cr}_{2}{ }^{16} \mathrm{O}_{3}(001)$ surface) could also probe for dissociation, $\mathrm{H}_{2}{ }^{18} \mathrm{O}$ was not available for this experiment. Instead, HREELS was used to successfully address the issue of the adsorbed state of water on $\alpha-\mathrm{Cr}_{2} \mathrm{O}_{3}(001)$.

\subsubsection{HREELS results}

The adsorbed state of water, in terms of molecular or dissociative forms, can be determined using vibrational spectroscopy. HREELS has been successfully used to address the adsorbed state of water on single crystal $\mathrm{TiO}_{2}(110)$ [22] and $\alpha-\mathrm{Fe}_{2} \mathrm{O}_{3}(012)$ [24]. Vibrational analysis of adsorbates on oxides using HREELS is made consider-

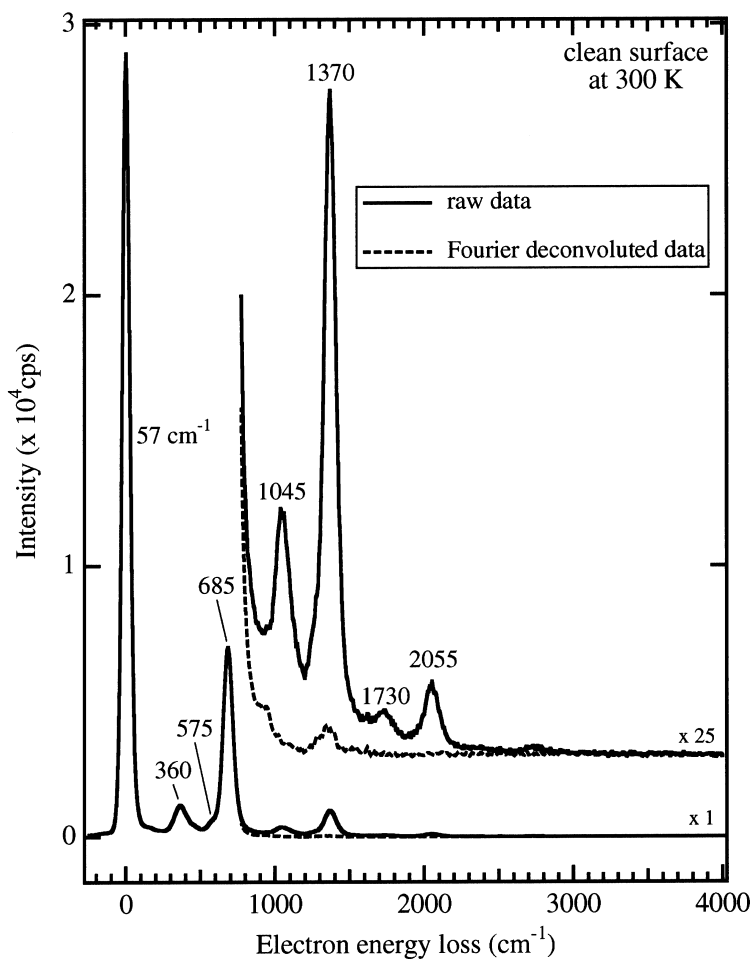

Fig. 5. HREELS spectra from the strained $\alpha-\mathrm{Cr}_{2} \mathrm{O}_{3}(001)$ surface with (dashed line) and without (solid line) Fourier deconvolution. All spectra were collected in specular direction at $300 \mathrm{~K}$ with a beam energy of $13.8 \mathrm{eV}$. 
ably easier by removal of multiple phonon losses using Fourier deconvolution [22]. Fig. 5 shows HREELS data from the clean strained $\alpha-\mathrm{Cr}_{2} \mathrm{O}_{3}(001)$ surface, obtained at $300 \mathrm{~K}$, before (solid traces) and after (dashed traces) Fourier deconvolution. Intense optical phonon losses are observed at 685 and $360 \mathrm{~cm}^{-1}$, with weaker losses at 575,455 and $160 \mathrm{~cm}^{-1}$. The 685 and $360 \mathrm{~cm}^{-1}$ losses are somewhat lower in frequency than the 708 and $416 \mathrm{~cm}^{-1}$ losses observed by Freund's group for $\alpha-\mathrm{Cr}_{2} \mathrm{O}_{3}$ thin films grown by oxidation of $\operatorname{Cr}(110)[27,28]$. Their data also appear to contain evidence for a weak loss on the low energy loss side of the $708 \mathrm{~cm}^{-1}$ feature, although this was not specifically discussed in their papers. The longitudinal optical phonon frequencies perpendicular to the $c$-axis of $\alpha-\mathrm{Cr}_{2} \mathrm{O}_{3}$ have been calculated by two groups using infrared data. Renneke and Lynch [29] obtained frequencies of 766, 602, 446 and $420 \mathrm{~cm}^{-1}$, while Serna et al. [30] obtained frequencies of $734,593,442$ and $306 \mathrm{~cm}^{-1}$. Serna et al. have assigned the lowest frequency feature to the displacement of the cations relative to the anion lattice, which as a result is unlikely to possess much oscillator strength. This phonon mode is not detected by HREELS. For the detected phonon modes, the frequencies measured by HREELS for the strained $\alpha-\mathrm{Cr}_{2} \mathrm{O}_{3}(001)$ surface are lower than either those calculated from IR data or those measured by HREELS for the $\alpha-\mathrm{Cr}_{2} \mathrm{O}_{3}(001)$ film on $\operatorname{Cr}(110)$ [27,28]. This may be the result of the $2 \%$ expansive strain in the in-plane structure of the $\alpha-\mathrm{Cr}_{2} \mathrm{O}_{3}(001)$ film when grown on $\alpha-\mathrm{Fe}_{2} \mathrm{O}_{3}(001)$. Unfortunately, this hypothesis could not be tested by performing HREELS on the unstrained $\alpha-\mathrm{Cr}_{2} \mathrm{O}_{3}(001)$ surface because of its charging limitations. The $160 \mathrm{~cm}^{-1}$ loss cannot be assigned to an optical phonon mode, but may result from the soft surface phonon mode previously detected by Wolter et al. [31] on the $\alpha-\mathrm{Cr}_{2} \mathrm{O}_{3}(001)$ film on $\mathrm{Cr}(110)$. A recent theoretical study has proposed that soft surface phonon modes may exist on oxides such as $\mathrm{TiO}_{2}(110)$ [32]. Fourier deconvolution removed virtually all of the multiple loss intensity above $800 \mathrm{~cm}^{-1}$, with the exception of the remnant of loss intensity at $1370 \mathrm{~cm}^{-1}$ (see the ' $\times 25$ ' spectrum in Fig. 5). This multiple phonon remnant is not removed by
Fourier deconvolution because it results from a combination of dipole and non-dipole scattering processes [33]. Note also the presence of a weak loss at about $915 \mathrm{~cm}^{-1}$. This loss will be assigned in the following discussion.

Fig. 6 shows Fourier deconvoluted HREELS data from the clean strained $\alpha-\mathrm{Cr}_{2} \mathrm{O}_{3}(001)$ surface (a) and from the clean surface exposed to a saturation exposure of $\mathrm{H}_{2} \mathrm{O}$ (b) and $\mathrm{D}_{2} \mathrm{O}$ (c) at $300 \mathrm{~K}$. The clean surface spectrum shows the phonon remnant at $1370 \mathrm{~cm}^{-1}$ and the weak loss at $915 \mathrm{~cm}^{-1}$. Exposure of this surface to $\mathrm{H}_{2} \mathrm{O}$ at $300 \mathrm{~K}$ results in new losses at 3600 and $2885 \mathrm{~cm}^{-1}$, and a more intense loss at $915 \mathrm{~cm}^{-1}$ (Fig. 6b). The $3600 \mathrm{~cm}^{-1}$ loss is reflective of an $\mathrm{OH}$ stretching mode [designated as $v(\mathrm{OH})$ ] of an isolated $\mathrm{OH}$ group. The term 'isolated' is used in the infrared (IR) spectroscopy literature of oxide

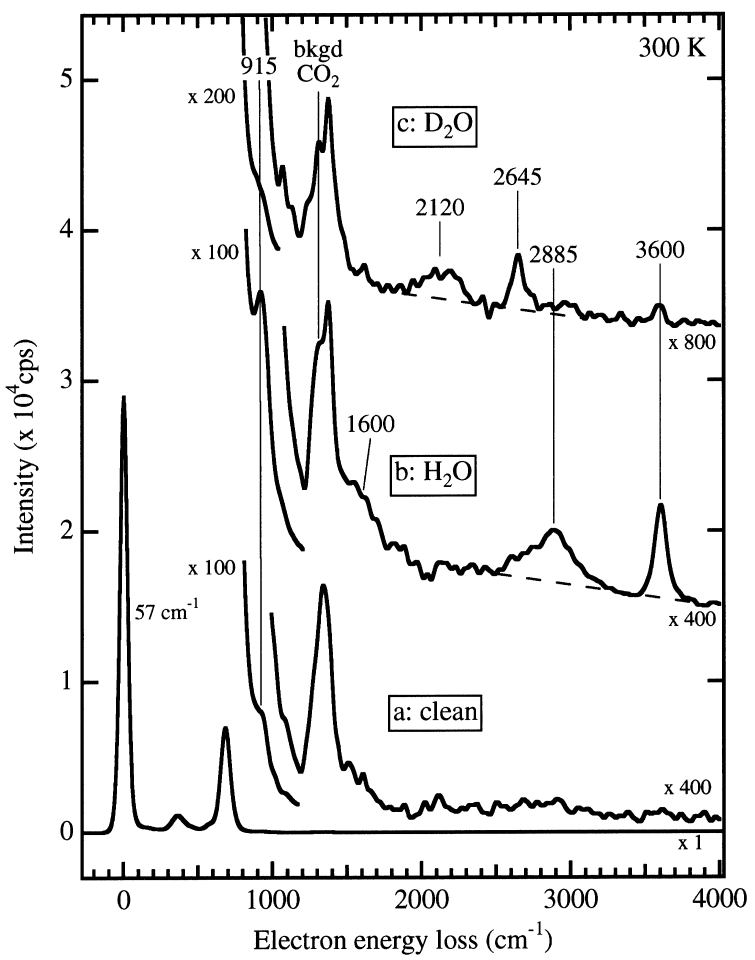

Fig. 6. Fourier deconvoluted HREELS spectra from the clean strained $\alpha-\mathrm{Cr}_{2} \mathrm{O}_{3}(001)$ surface (a), from the clean surface exposed to saturation $\mathrm{H}_{2} \mathrm{O}$ at $300 \mathrm{~K}(\mathrm{~b})$, and from the clean surface exposed to saturation $\mathrm{D}_{2} \mathrm{O}$ at $300 \mathrm{~K}$ (c). All spectra were collected in specular direction at $300 \mathrm{~K}$ with a beam energy of $13.8 \mathrm{eV}$. 
powders in reference to an $\mathrm{OH}$ group whose proton is not involved in hydrogen-bonding [34]. (For these isolated $\mathrm{OH}$ groups, no distinction is usually made regarding whether or not the hydroxyl's oxygen atom is involved in hydrogen-bonding to other species.) The absence of hydrogen-bonding in an $\mathrm{OH}$ group is almost always reflected by a $v(\mathrm{OH})$ mode above $3500 \mathrm{~cm}^{-1}$. On the other hand, the broad loss at $2885 \mathrm{~cm}^{-1}$ is uncharacteristically low for typical hydrogen-bonded $\mathrm{OH}$ groups, and indicates an $\mathrm{OH}$ group involved in an unusually strong hydrogen-bonding interaction. (This is discussed in greater detail in Section 3.1.4.) Several IR studies on the interaction of water with $\alpha-\mathrm{Cr}_{2} \mathrm{O}_{3}$ powders have observed $\mathrm{OH}$ stretching features corresponding to isolated and hydrogenbonded species [35-37]. These studies have detected sharp features between 3600 and $3650 \mathrm{~cm}^{-1}$ that have been assigned to terminal $\mathrm{OH}$ groups on $\{001\}$ planes. However, the stretching modes of hydrogen-bonded $\mathrm{OH}$ species are generally observed in the $3200-3400 \mathrm{~cm}^{-1}$ region, and these studies do not observe $v(\mathrm{OH})$ features below $3000 \mathrm{~cm}^{-1}$. This may be because the $\mathrm{O}-\mathrm{H}$ oscillator strength of strongly hydrogen-bonded $\mathrm{OH}$ groups is often too weak to be detected by IR [34]. The $915 \mathrm{~cm}^{-1}$ loss is due to the bending mode $[\delta(\mathrm{OH})]$ of an $\mathrm{OH}$ group, and may be from either the isolated or hydrogen-bonded species (or both). The $\mathrm{H}_{2} \mathrm{O}$ HREELS spectrum in Fig. $6 \mathrm{~b}$ also shows a broad and weak feature in the vicinity of $1600 \mathrm{~cm}^{-1}$ that can be assigned to the $\delta(\mathrm{HOH})$ mode of chemisorbed water.

Losses are observed in HREELS at 2645 and $2120 \mathrm{~cm}^{-1}$, with weaker intensity features at 3600 and $915 \mathrm{~cm}^{-1}$, when the clean surface is exposed to $\mathrm{D}_{2} \mathrm{O}$ (Fig. $6 \mathrm{c}$ ). The latter set are presumably due to background $\mathrm{H}_{2} \mathrm{O}$ adsorption and/or residual hydrogen-containing water dosed with the $\mathrm{D}_{2} \mathrm{O}$. The former set of losses is consistent with an $\mathrm{H} / \mathrm{D}$ shift (both of 1.36) expected for the $v(\mathrm{OD})$ counterparts to the $v(\mathrm{OH})$ losses at 3600 and $2885 \mathrm{~cm}^{-1}$ (Fig. 6b). An isotope shift for the $\delta(\mathrm{OH})$ mode at $915 \mathrm{~cm}^{-1}$ should result in a $\delta(\mathrm{OD})$ mode at about $700 \mathrm{~cm}^{-1}$, which unfortunately is obscured by the intense oxide phonon loss at $685 \mathrm{~cm}^{-1}$. Note also that the feature at $1600 \mathrm{~cm}^{-1}$ has shifted. The $\delta(D O D)$ mode should be at about $1200 \mathrm{~cm}^{-1}$, but is not readily apparent in the HREELS spectrum of Fig. 6c. Dosing the $\mathrm{D}_{2} \mathrm{O} / \mathrm{OD}$-covered surface with a large exposure of $\mathrm{H}_{2} \mathrm{O}$ at $300 \mathrm{~K}$ results in HREELS intensity being shifted back to the 3600 and $2885 \mathrm{~cm}^{-1}$ losses as a result of $\mathrm{H}-\mathrm{D}$ exchange (data not shown). The loss pairs at $3600 / 2885 \mathrm{~cm}^{-1}$ and $2645 / 2120 \mathrm{~cm}^{-1}$ can be toggled back and forth by consecutive exposures to $\mathrm{H}_{2} \mathrm{O}$ and $\mathrm{D}_{2} \mathrm{O}$, indicating that water adsorption, $\mathrm{H} / \mathrm{D}$ exchange and water desorption are facile at $300 \mathrm{~K}$ (as one might expect from inspection of the TPD data in Fig. 3). Based on these observations, the 2885 and $2120 \mathrm{~cm}^{-1}$ losses can be assigned to strongly hydrogen-bonded $\mathrm{OH}$ and OD species, respectively, as opposed to impurities that give rise to $\mathrm{C}-\mathrm{H}$ and $\mathrm{C}-\mathrm{D}$ stretches. A structural model for these species is presented below in Section 3.1.4.

The loss labeled 'bkgd $\mathrm{CO}_{2}$ ' in Fig. 6 is at $1310 \mathrm{~cm}^{-1}$, and is from background adsorption of $\mathrm{CO}_{2}$ during the course of the HREELS data acquisition. The species responsible for this loss is presumably a carboxylate based on previously published work by Freund's group for $\mathrm{CO}_{2}$ adsorbed on $\alpha-\mathrm{Cr}_{2} \mathrm{O}_{3}(001)$ films on $\mathrm{Cr}(110)$ $[28,38]$. In separate work, we have found no evidence for a chemical reaction between $\mathrm{CO}_{2}$ and water on $\alpha-\mathrm{Cr}_{2} \mathrm{O}_{3}(001)$, suggesting that (under UHV conditions) $\mathrm{CO}_{2}$ only influences water surface chemistry by simple site blocking [39].

The HREELS analysis in Fig. 6 was performed at $300 \mathrm{~K}$ because the sample experienced charging if exposed to the HREELS electron beam at the sample base temperature obtained by LN2 cooling $(120 \mathrm{~K})$. However, HREELS analysis at $300 \mathrm{~K}$ did not permit characterization of the water species that desorbs in the 295 K TPD peak. Fortunately, only limited charging of the sample occurred at $230 \mathrm{~K}$, which is a sample temperature that retains the majority of the $295 \mathrm{~K}$ water TPD state. This sample temperature could be maintained within $\pm 20 \mathrm{~K}$ by regulating the amount of LN 2 in the manipulator. Fig. 7 shows the HREELS spectrum obtained from a saturation exposure of $\mathrm{H}_{2} \mathrm{O}$ on the strained $\alpha-\mathrm{Cr}_{2} \mathrm{O}_{3}(001)$ surface at $230 \mathrm{~K}$. It should be pointed out that the elastic peak count rate from the clean surface was considerably attenuated at $230 \mathrm{~K}$ and the resolution was slightly 


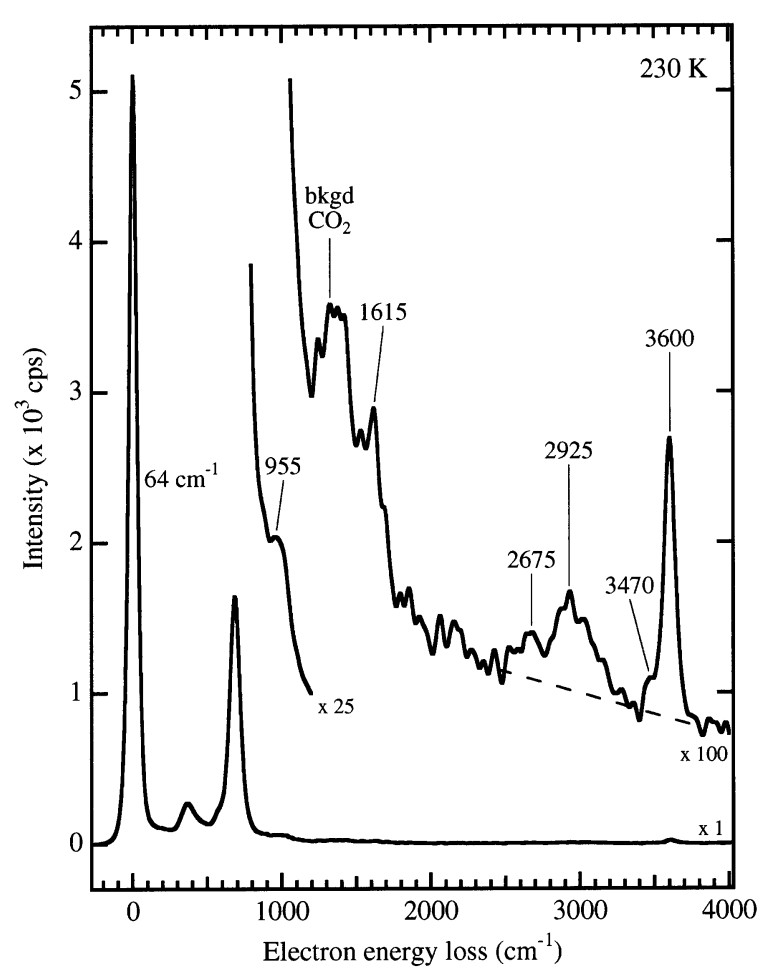

Fig. 7. Fourier deconvoluted HREELS spectrum from the clean strained $\alpha-\mathrm{Cr}_{2} \mathrm{O}_{3}(001)$ surface exposed to saturation $\mathrm{H}_{2} \mathrm{O}$ at $230 \mathrm{~K}$. The spectrum was collected in specular direction at $300 \mathrm{~K}$ with a beam energy of $13.8 \mathrm{eV}$.

degraded compared with the $300 \mathrm{~K}$ spectrum. The signal-to-noise ratio was also lower at $230 \mathrm{~K}$ compared with at $300 \mathrm{~K}$. These changes in the clean surface spectrum indicate that some charging occurs at $230 \mathrm{~K}$. Nevertheless, the $230 \mathrm{~K}$ HREELS spectrum is similar to that obtained at $300 \mathrm{~K}$ with a few notable exceptions. First, the broad loss observed in Fig. 6 at $2885 \mathrm{~cm}^{-1}$ for $300 \mathrm{~K} \mathrm{H}_{2} \mathrm{O}$ adsorption is split into two losses at 2925 and $2675 \mathrm{~cm}^{-1}$ for $230 \mathrm{~K} \mathrm{H}_{2} \mathrm{O}$ adsorption. Second, the $915 \mathrm{~cm}^{-1}$ loss is shifted to slightly higher loss energy at $955 \mathrm{~cm}^{-1}$. Third, the $\delta(\mathrm{HOH})$ mode of molecular water is more intense after adsorption at $230 \mathrm{~K}$ compared with the $300 \mathrm{~K}$ spectrum. Finally, a weak loss is observed at $3470 \mathrm{~cm}^{-1}$ as a shoulder on the intense $3600 \mathrm{~cm}^{-1}$ loss. Although the $3470 \mathrm{~cm}^{-1}$ loss is at the noise level, its presence was reproducibly observed in the HREELS spectrum over a series of six independent surface measurements. In contrast to these changes, the $3600 \mathrm{~cm}^{-1}$ loss is unaffected by the presence of the additional $\mathrm{H}_{2} \mathrm{O}$ adsorbed in the $295 \mathrm{~K}$ TPD state.

The presence of a more intense $1615 \mathrm{~cm}^{-1}$ loss in Fig. 7 strongly suggests that the $295 \mathrm{~K}$ TPD state is due to molecular adsorbed water. This molecularly adsorbed water appears to perturb the hydrogen-bonded $\mathrm{OH}$ groups in that their $v(\mathrm{OH})$ loss is altered. Since the $v(\mathrm{OH})$ loss for the isolated $\mathrm{OH}$ is unaffected by the presence of molecular water, the $\delta(\mathrm{OH})$ mode observed at $955 \mathrm{~cm}^{-1}$, which is shifted with coadsorbed $\mathrm{H}_{2} \mathrm{O}$, is probably from the hydrogen-bonded $\mathrm{OH}$ group and not from the isolated $\mathrm{OH}$ group.

\subsubsection{XPS results}

Based on the HREELS results discussed in the previous section, the $345 \mathrm{~K}$ TPD peak can be assigned to desorption of water from recombination of two distinctively different $\mathrm{OH}$ groups. HREELS results also suggest that the $295 \mathrm{~K}$ TPD peak is due to desorption of molecularly adsorbed water. In order to confirm these assignments, XPS analysis was performed on the strained $\alpha-\mathrm{Cr}_{2} \mathrm{O}_{3}(001)$ surface. Fig. 8 shows $\mathrm{O} 1 \mathrm{~s}$ photoemission spectra for the clean surface detected at normal (a) and glancing (b) angle of detection. (In order to compensate for the varying degrees of charging encountered in these measurements, the $\mathrm{O} 1 \mathrm{~s}$ spectrum was shifted by aligning the $\mathrm{Cr} 2 \mathrm{p}_{3 / 2}$ binding energy to that observed in the literature [40].) Although the spectral resolution is slightly degraded at glancing angle detection due to focal length variations, both clean surface spectra yield a sharp $O$ is feature at about $531.5 \mathrm{eV}$. The glancing angle spectrum appears to possess slightly more intensity on the high binding energy side of the $\mathrm{O} 1 \mathrm{~s}$ peak. Exposure of the clean surface to $15 \mathrm{~L}$ of $\mathrm{H}_{2} \mathrm{O}$ at $300 \mathrm{~K}$ broadens the $\mathrm{O} 1 \mathrm{~s}$ feature but also results in increased intensity in the high binding energy shoulder (Fig. 8c). Exposure of the clean surface to $15 \mathrm{~L}$ of $\mathrm{H}_{2} \mathrm{O}$ at $250 \mathrm{~K}$ further alters the $\mathrm{O} 1 \mathrm{~s}$ spectrum in that the peak is considerably broadened, and a new feature appears at about $534 \mathrm{eV}$ (Fig. 8d). The $\mathrm{O} 1 \mathrm{~s}$ feature obtained at normal emission after $250 \mathrm{~K}$ adsorption of water (not shown) is essentially identical to that obtained from the clean 


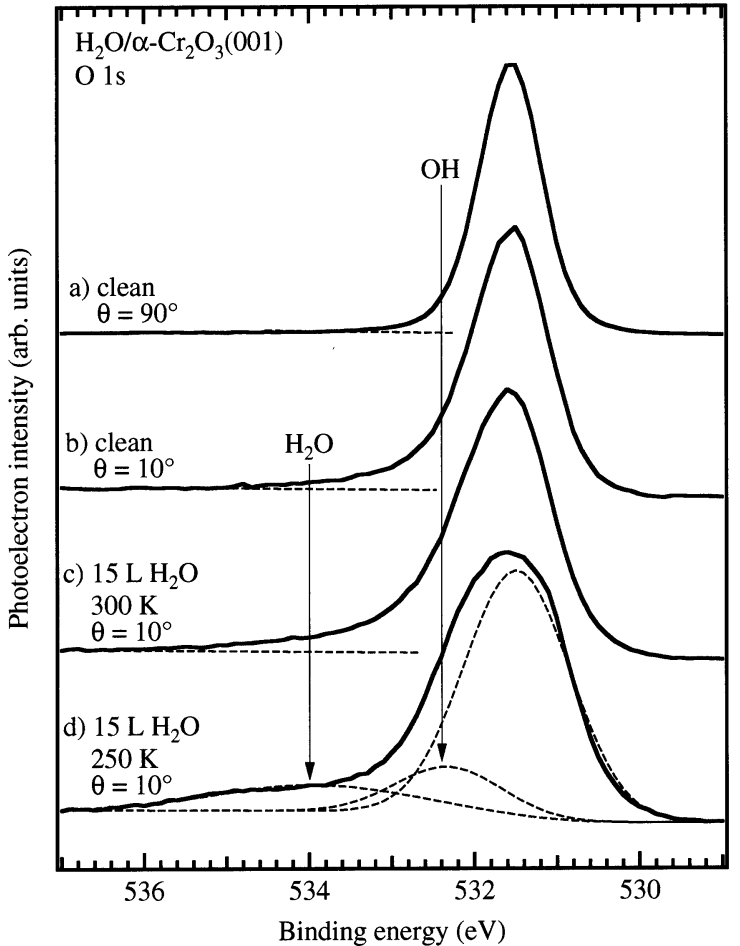

Fig. 8. O 1s XPS spectra for the clean strained $\alpha-\mathrm{Cr}_{2} \mathrm{O}_{3}(001)$ surface at (a) normal $\left(90^{\circ}\right)$ and (b) glancing $\left(10^{\circ}\right)$ angle of detection, and for the clean strained $\alpha-\mathrm{Cr}_{2} \mathrm{O}_{3}(001)$ surface exposed to $15 \mathrm{~L} \mathrm{H}_{2} \mathrm{O}$ at $300 \mathrm{~K}$ (c) and at $250 \mathrm{~K}$ (d), both at the glancing angle. The center of each peak was referenced to a binding energy of about $531.5 \mathrm{eV}$.

surface (Fig. 8a) with the exception that a very weak feature is detected at about $535 \mathrm{eV}$. Since normal incidence detection is mainly sensitive to the bulk, the width of the $\mathrm{O} 1 \mathrm{~s}$ spectrum at glancing angle in Fig. 8d must be associated with the oxygen-containing species in the outermost surface layer(s). The broadness of the peak may result from inhomogeneous lifting or partial lifting of the surface relaxation by the water/hydroxyl adlayer.

The high binding energy shoulder in the $\mathrm{O} 1 \mathrm{~s}$ spectrum after $\mathrm{H}_{2} \mathrm{O}$ adsorption at $300 \mathrm{~K}$ can be assigned to the $\mathrm{O} 1 \mathrm{~s}$ feature from a surface $\mathrm{OH}$ group based on other studies that have detected $\mathrm{OH}$ groups on surfaces using XPS [41]. The feature at $534 \mathrm{eV}$ after $\mathrm{H}_{2} \mathrm{O}$ adsorption at $250 \mathrm{~K}$ is consistent with molecularly adsorbed water [41]. The intensity of the $\mathrm{OH}$ feature is weak in the $300 \mathrm{~K}$ spectrum (Fig. 8c) because the rate of desorption of water in the $345 \mathrm{~K} \mathrm{H}_{2} \mathrm{O}$ TPD peak is non-zero at $300 \mathrm{~K}$ for a fully hydroxylated surface. This tends to restrict the sustainable coverage of dissociated water at $300 \mathrm{~K}$ under UHV conditions to a subsaturation level. This problem is not significant for the case of XPS analysis of the $298 \mathrm{~K}$ TPD peak at $250 \mathrm{~K}$ (see Fig. 3). Since a $250 \mathrm{~K}$ adsorption temperature precludes the presence of physisorbed states of water (detected in TPD below $250 \mathrm{~K}$ ), the $295 \mathrm{~K}$ TPD state can be assigned to desorption of molecularly adsorbed water, in agreement with the assignment arrived at from HREELS data. The coverage of $\mathrm{H}_{2} \mathrm{O}$ and $\mathrm{OH}$ at $250 \mathrm{~K}$ can be estimated using the XPS data in Fig. 8d. The spectrum was curve fit using three gaussians. The coverages of $\mathrm{H}_{2} \mathrm{O}$ and $\mathrm{OH}$ on the surface at $250 \mathrm{~K}$ can be determined from the attenuation of the $\mathrm{O} 1 \mathrm{~s}$ signal from the lattice. The escape length was estimated by comparing the $\mathrm{O} 1 \mathrm{~s}$ intensity of the oxygen exposed surface relative to that of the clean surface. Previous infrared studies suggest that oxygen exposure to the $\alpha-\mathrm{Cr}_{2} \mathrm{O}_{3}(001) / \mathrm{Cr}(110)$ surface results in each surface $\mathrm{Cr}$ cation being 'capped' with an atomic $\mathrm{O}$ species via dissociative oxygen chemisorption [19]. Assuming this is the case and the surface atomic oxygen coverage is equal to the cation density in terminal layer, then the $\mathrm{O} 1 \mathrm{~s}$ signal from the atomic $\mathrm{O}$ species (at $532.4 \mathrm{eV}$ ) can be used to estimate the escape length of $\mathrm{O} 1 \mathrm{~s}$ photoelectrons originating from the oxide (at $531.5 \mathrm{eV}$ ). Using the methodology of Tanuma et al. [42], a value of $18 \AA$ is obtained for the escape length of the $\mathrm{O} 1 \mathrm{~s}$ photoelectrons. This is consistent with the 14$17 \AA$ value estimated by Tanuma for the isostructural $\alpha-\mathrm{Al}_{2} \mathrm{O}_{3}$. Based on this value for the $\mathrm{O} 1 \mathrm{~s}$ escape length, the coverages of $\mathrm{OH}$ and $\mathrm{H}_{2} \mathrm{O}$ at $250 \mathrm{~K}$ are both approximately equivalent to the surface coverage of three-coordinate $\mathrm{Cr}^{3+}$ sites (about $4.6 \times 10^{14} \mathrm{~cm}^{-2}$ ), in agreement with the TPD data.

\subsubsection{Model for adsorbed water on $\alpha-\mathrm{Cr}_{2} \mathrm{O}_{3}(001)$}

Based on the TPD, HREELS and XPS results presented above, we propose the following model for how $\mathrm{H}_{2} \mathrm{O}$ interacts with the Cr-terminated $\alpha-\mathrm{Cr}_{2} \mathrm{O}_{3}(001)$ surface. TPD results suggest that 
the monolayer saturation coverage of water obtained by exposure at $120 \mathrm{~K}$ in UHV is twice that of the surface density of exposed $\mathrm{Cr}^{3+}$ cations. Water in the chemisorbed monolayer desorbs in two TPD states of approximately equal proportions at 345 and $295 \mathrm{~K}$ (Fig. 3). HREELS has identified two $v(\mathrm{OH})$ modes at 3600 and $2885 \mathrm{~cm}^{-1}$ for water adsorbed in the $345 \mathrm{~K} \mathrm{H}_{2} \mathrm{O}$ TPD state (Fig. 6b). These features shift to 2645 and $2120 \mathrm{~cm}^{-1}$ with $\mathrm{D}_{2} \mathrm{O}$ adsorption. The two $v(\mathrm{OH})$ modes are in strong contrast to each other, one representing an isolated $\mathrm{O}-\mathrm{H}$ bond and one representing an $\mathrm{O}-\mathrm{H}$ bond that is involved in an unusually strong hydrogen-bonding interaction. (For the relationship between the $v(\mathrm{OH})$ frequency and the strength of the hydrogen-bonding interaction, see Novak [43], as discussed by Thiel and Madey [41].) These HREELS features can be interpreted in two ways. In the first case, the 3600 and $2885 \mathrm{~cm}^{-1}$ losses can be assigned to two different $v(\mathrm{OH})$ modes of a molecularly adsorbed water molecule in which one $\mathrm{O}-\mathrm{H}$ bond is strongly hydrogen-bonded to either a surface anion site or to another $\mathrm{H}_{2} \mathrm{O}$ molecule and the second $\mathrm{O}-\mathrm{H}$ bond is free of hydrogen-bonding interactions. This situation exists for ice surfaces where dangling $\mathrm{O}-\mathrm{H}$ bonds have been observed by vibrational spectroscopy [41]. For the second case, the two losses can be assigned to two different $\mathrm{OH}$ groups, one of which is involved in hydrogenbonding and the other of which is not. Given that the loss intensity in the vicinity of $1600 \mathrm{~cm}^{-1}$ (region in which the $\delta(\mathrm{HOH})$ mode of molecular $\mathrm{H}_{2} \mathrm{O}$ is observed) is weak, whereas an intense loss is observed at $915 \mathrm{~cm}^{-1}$ (region in which the $\delta(\mathrm{OH})$ mode of $\mathrm{OH}$ is observed), water in the $345 \mathrm{~K}$ TPD peak can be assigned to recombinative desorption of dissociated water molecules. This assignment is consistent with the XPS results of Fig. 8. However, this does not mean that molecular water is not present on the surface at $300 \mathrm{~K}$. Some intensity is detected in the $\delta(\mathrm{HOH})$ region, possibly indicating that a small steady-state population of molecular water may exist on the surface at $300 \mathrm{~K}$, as has been proposed for water on $\alpha-\mathrm{Fe}_{2} \mathrm{O}_{3}(012)$ [24].

Recent molecular dynamics calculations by Hass et al. [9] predict that $\mathrm{H}_{2} \mathrm{O}$ dissociates on the isostructural $\alpha-\mathrm{Al}_{2} \mathrm{O}_{3}(001)$ surface by proton transfer from a $\mathrm{H}_{2} \mathrm{O}$ molecule (adsorbed at a cation site) to a neighboring surface anion site. The most favorable water dissociation mechanism appears to involve proton transfer to the next-tonearest neighbor anion site away from the cation site (what Hass et al. refer to as a ' $1-4$ transfer'). This corresponds to the first anion site that is found in moving along the [100] direction away from a surface cation site (see Figs. 1 and 9). This is as opposed to proton transfer to a lattice oxygen atom in the same coordination sphere of the $\mathrm{Cr}^{3+}$ cation (a '1-2 transfer'), which Hass et al. predict is less favorable. Bredow, in calculating the minimum energy for the dissociation of a single water molecule on the Cr-terminated $\alpha-\mathrm{Cr}_{2} \mathrm{O}_{3}(001)$ surface, examined only the 1-2 transfer process and found it to be slightly less stable than molecular adsorption [1]. Bredow also found that the fully hydrated surface was considerably more stable than the fully hydroxylated surface. The case of both molecular and dissociated water on a single cation site was not considered by either Bredow or Hass et al.

Fig. 9 shows a schematic model for the $\mathrm{OH}$
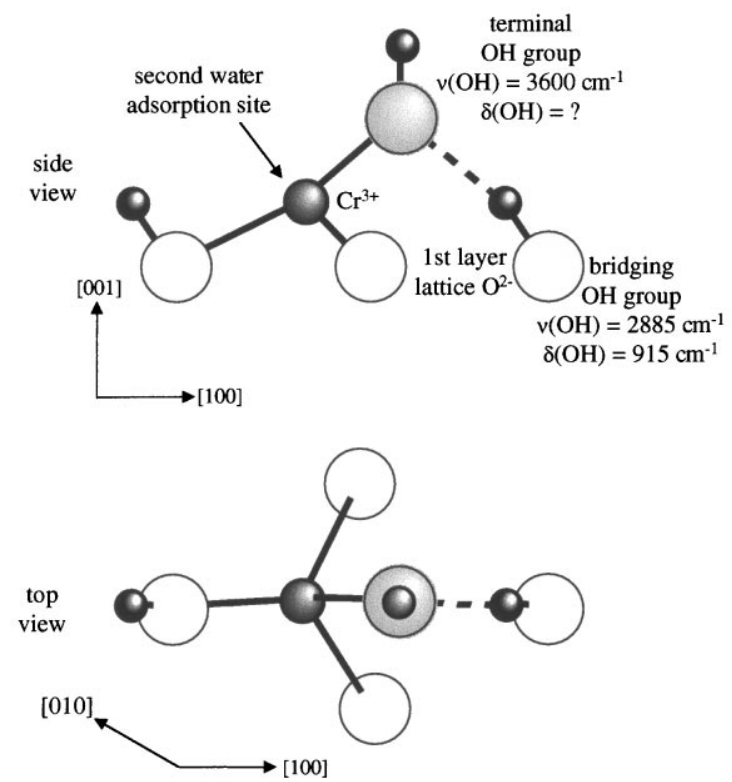

Fig. 9. Schematic model for the structure of $\mathrm{OH}$ groups on the Cr-terminated $\alpha-\mathrm{Cr}_{2} \mathrm{O}_{3}(001)$ surface. 
groups generated from water dissociation on the $\alpha-\mathrm{Cr}_{2} \mathrm{O}_{3}(001)$ based on our experimental results and partially on the model proposed by Hass et al. [9]. Our results suggest that water dissociates on $\alpha-\mathrm{Cr}_{2} \mathrm{O}_{3}(001)$, forming a terminal $\mathrm{OH}$ group bound at the cation site and a bridging $\mathrm{OH}$ group at a first layer lattice anion site. The ' $1-4$ ' model of Hass et al. has been modified by inclusion of hydrogen-bonding between the two types of $\mathrm{OH}$ group in an effort to rationalize the HREELS data (Figs. 6 and 7) that shows evidence for hydrogenbonding between the two types of hydroxyl. By tilting the terminal $\mathrm{OH}$ group from its atop position by about $45^{\circ}$ toward the bridging $\mathrm{OH}$ group, an $\mathrm{O}-\mathrm{O}$ distance of about $2.8 \AA$ can be obtained between the two hydroxyl groups with the proton on the bridging $\mathrm{OH}$ group pointing at the terminal $\mathrm{OH}$. This geometry, although purely speculative and somewhat arbitrarily chosen, provides a hydrogen-bonded pair of hydroxyls whose structure is consistent with the HREELS data, and provides a pairing of $\mathrm{OH}$ groups that is consistent with the first-order desorption kinetics of the $345 \mathrm{~K}$ TPD state (that is, first-order in the coverage of paired, hydrogen-bonded $\mathrm{OH}$ groups). The latter is consistent with what is observed for the recombinative desorption of water on the $(1 \times 1)$ surface of $\alpha-\mathrm{Fe}_{2} \mathrm{O}_{3}(012)$ [24]. Also, the tilting of the terminal $\mathrm{OH}$ group towards the bridging $\mathrm{OH}$ group opens a potential coordination site on the $\mathrm{Cr}^{3+}$ cation in which a second water molecule can adsorb, in accordance with TPD, HREELS and XPS data. Notice that a molecularly adsorbed water in this site will 'hang' over the bridging $\mathrm{OH}$ group potentially altering the structure and fundamental vibrational mode frequencies of that hydroxyl. This may explain the small changes observed in the $v(\mathrm{OH})$ and $\delta(\mathrm{OH})$ modes of the hydrogen-bonded $\mathrm{OH}$ group upon coadsorption of molecular water.

\subsection{Interaction of water with the unstrained $\alpha-\mathrm{Cr}_{2} \mathrm{O}_{3}(001)$ surface}

As mentioned in the experimental section, the $\alpha-\mathrm{Cr}_{2} \mathrm{O}_{3}$ film grown on $\alpha-\mathrm{Fe}_{2} \mathrm{O}_{3} / \alpha-\mathrm{Al}_{2} \mathrm{O}_{3}(001)$ is $2 \%$ expanded in-plane relative to the bulkterminated $\alpha-\mathrm{Cr}_{2} \mathrm{O}_{3}(001)$ surface. However, the
$\alpha-\mathrm{Cr}_{2} \mathrm{O}_{3}$ film grown on $\alpha-\mathrm{Al}_{2} \mathrm{O}_{3}(001)$ yields an $\alpha-\mathrm{Cr}_{2} \mathrm{O}_{3}(001)$ surface with a bulk-terminated $\alpha-\mathrm{Cr}_{2} \mathrm{O}_{3}(001)$ surface structure [14]. Since the presence of strain may influence the surface chemistry of adsorbates, the TPD of water from the unstrained $\alpha-\mathrm{Cr}_{2} \mathrm{O}_{3}(001)$ surface is compared in Fig. 10 with that observed for the strained $\alpha-\mathrm{Cr}_{2} \mathrm{O}_{3}(001)$ surface (data taken from Fig. 3). In general, the two TPD spectra are very similar to each other, each showing the same number of desorption states with approximately the same relative peak intensities and desorption temperatures. The two low temperature features at 185 and $210 \mathrm{~K}$ from both surfaces overlay each other almost exactly. The pair of high temperature features, however, are slightly shifted from each other, with the peak temperatures from the unstrained $\alpha-\mathrm{Cr}_{2} \mathrm{O}_{3}(001)$ surface approximately 10 to $15 \mathrm{~K}$ higher than those from strained $\alpha-\mathrm{Cr}_{2} \mathrm{O}_{3}(001)$. These peak temperature differences likely arise

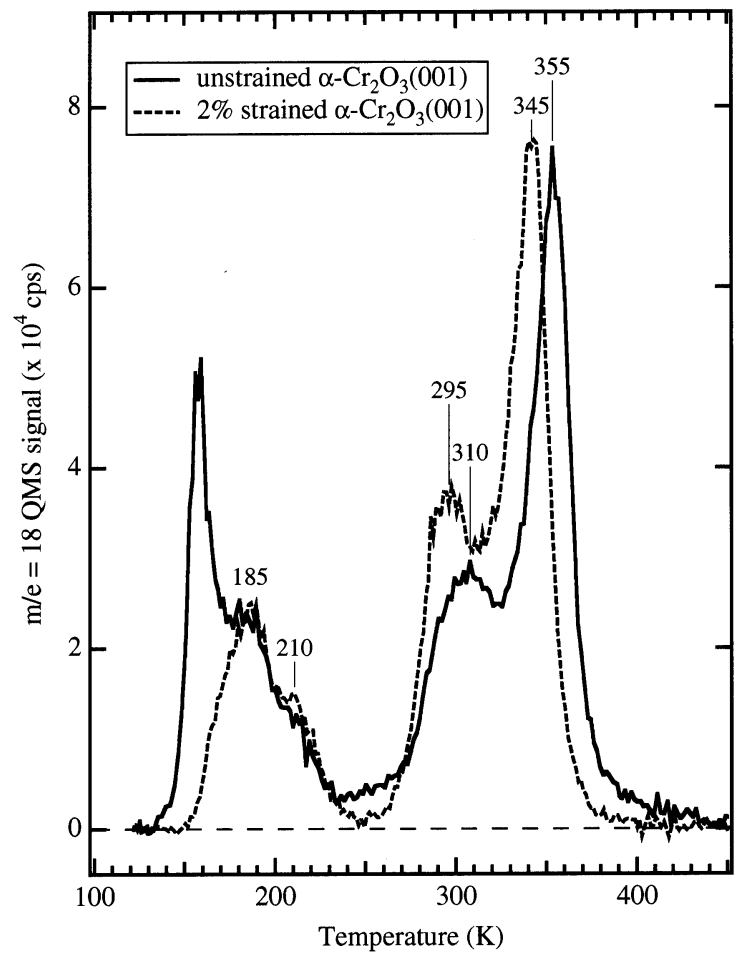

Fig. 10. Comparison of the $\mathrm{H}_{2} \mathrm{O}$ TPD spectra $(m / e=18)$ from about $2 \times 10^{15}$ molecules $/ \mathrm{cm}^{2}$ exposure of $\mathrm{H}_{2} \mathrm{O}$ to the strained (dashed line) and unstrained (solid line) $\alpha-\mathrm{Cr}_{2} \mathrm{O}_{3}(001)$ surfaces. 
from a slight difference in the temperature measured at the two samples. Although not attempted, a compilation of TPD spectra from several sample mountings would likely yield a small spread in the $\mathrm{H}_{2} \mathrm{O}$ TPD peak temperatures centered about the peak temperatures for both surfaces. Yet such temperature variations have not been observed in the water TPD peak temperature in the course of our studies on $\mathrm{TiO}_{2}(110)$ using the same crystal mounting method (see experimental section) on numerous different crystal mountings $[22,26]$. Given that the thermal conductivity of $\mathrm{TiO}_{2}$ rutile is about a factor of 4 less than that of $\alpha-\mathrm{Al}_{2} \mathrm{O}_{3}$ sapphire [44], which is the substrate for both $\alpha-\mathrm{Cr}_{2} \mathrm{O}_{3}$ films, one might expect larger thermal incongruities in $\mathrm{TiO}_{2}$ substrates. Therefore, it is possible that the small $\mathrm{H}_{2} \mathrm{O}$ TPD peak differences observed for the two $\alpha-\mathrm{Cr}_{2} \mathrm{O}_{3}(001)$ surfaces could in fact be due to the $2 \%$ in-plane structural difference between the two surfaces. In any event, it is clear that a small expansive strain does not significantly alter the desorption properties of water from the $\alpha-\mathrm{Cr}_{2} \mathrm{O}_{3}(001)$ surface, and that both surfaces exhibit the same kinds of water chemistry discussed in previous sections.

\subsection{Effect of preadsorbed oxygen on water TPD}

Since oxygen is a prevalent molecule in both humid and aqueous environments, and since many oxide surface preparation schemes utilize $\mathrm{O}_{2}$, the effect of preadsorbed oxygen on the TPD properties of water has been examined. Dillmann et al. have previously observed that oxygen binds very strongly to $\mathrm{Cr}^{3+}$ sites on $\alpha-\mathrm{Cr}_{2} \mathrm{O}_{3}(001)$ films grown on $\operatorname{Cr}(110)$ [19]. These authors detected both molecular and dissociative forms of adsorbed oxygen using TPD, IR and ELS. The molecular channel gives rise to an $\mathrm{O}_{2}$ TPD feature at $320 \mathrm{~K}$, whereas the disappearance of the dissociative species (oxygen adatoms) is not observed in TPD. However, Dillmann et al. have observed the attenuation of a $v(\mathrm{Cr}=\mathrm{O})$ mode at $1005 \mathrm{~cm}^{-1}$ between 700 and $850 \mathrm{~K}$ due to desorption of these oxygen adatoms.

Fig. 11a shows TPD spectra from a $1.1 \times 10^{15}$ molecules $/ \mathrm{cm}^{2}$ exposure of $\mathrm{H}_{2} \mathrm{O}$ adsorbed on the unstrained $\alpha-\mathrm{Cr}_{2} \mathrm{O}_{3}(001)$ surface

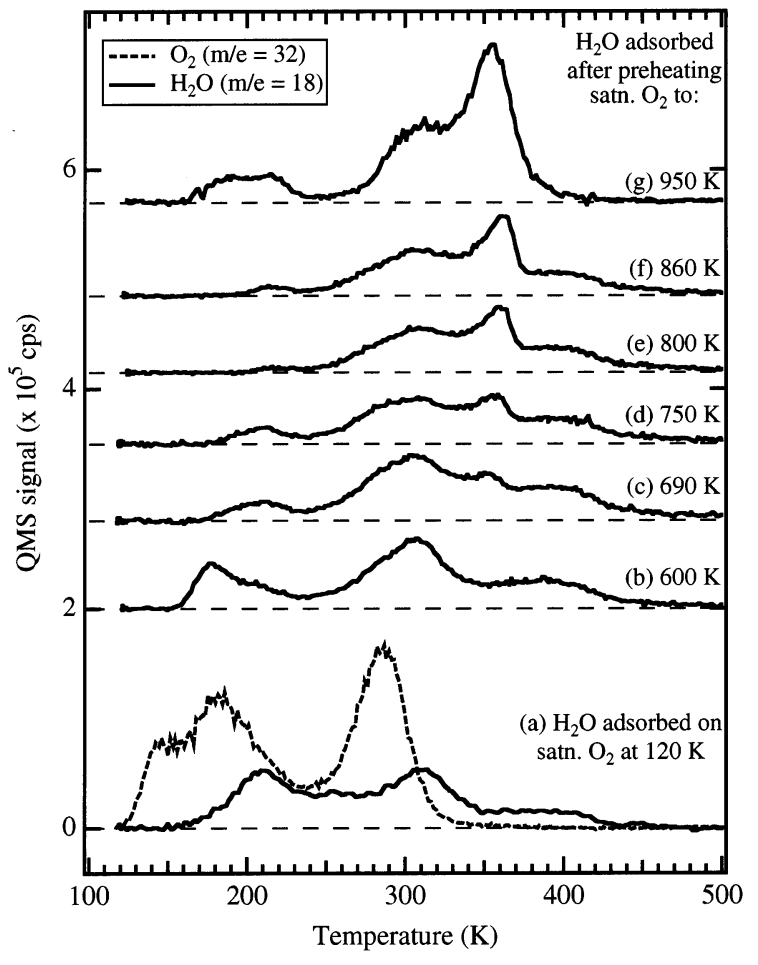

Fig. 11. $\mathrm{H}_{2} \mathrm{O} \quad(m / e=18)$ and $\mathrm{O}_{2} \quad(m / e=32)$ TPD spectra from $1.0 \times 10^{15}$ molecules $/ \mathrm{cm}^{2} \mathrm{H}_{2} \mathrm{O}$ adsorbed to the $\mathrm{O}_{2^{-}}$ presaturated, strained $\alpha-\mathrm{Cr}_{2} \mathrm{O}_{3}(001)$ surface at $120 \mathrm{~K}$ (a), and for the same $\mathrm{H}_{2} \mathrm{O}$ exposure adsorbed at $120 \mathrm{~K}$ after heating the $\mathrm{O}_{2}$-presaturated surface to: (b) 600, (c) 692, (d) 750, (e) 800, (f) 857 and (g) $950 \mathrm{~K}$.

presaturated with $\mathrm{O}_{2}$ at $120 \mathrm{~K}$. Oxygen was dosed by backfilling the chamber with a $20 \mathrm{~L}$ exposure. The $\mathrm{O}_{2}(m / e=32)$ TPD trace is shown as a dashed line, and the $\mathrm{H}_{2} \mathrm{O}(m / e=18)$ TPD trace is shown as a solid line. The main $\mathrm{O}_{2}$ TPD features are at 145,180 and $285 \mathrm{~K}$. The lower temperature features are from physisorbed states on the $\alpha-\mathrm{Cr}_{2} \mathrm{O}_{3}(001)$ surface (or possibly from the sample holder [45]), whereas the $285 \mathrm{~K}$ TPD state has been assigned to molecularly bound $\mathrm{O}_{2}$ at a $\mathrm{Cr}^{3+}$ site [19]. The $\mathrm{O}_{2}$ TPD peak temperature observed from the strained $\alpha-\mathrm{Cr}_{2} \mathrm{O}_{3}(001)$ surface is about $35 \mathrm{~K}$ lower than that observed by Dillmann et al. This could be due, in part, to the higher ramp rate used by those authors $(4 \mathrm{~K} / \mathrm{s})$, but may also be due to differences in temperature measurements. The water TPD spectrum from $\mathrm{H}_{2} \mathrm{O}$ dosed on the $\mathrm{O}_{2}$-presaturated surface (Fig. 11a) is significantly 
different from that observed on the clean surface (Figs. 10 and $11 \mathrm{~g}$ ). The TPD peaks at 210 and $310 \mathrm{~K}$, assigned to physisorbed and chemisorbed $\mathrm{H}_{2} \mathrm{O}$ molecules (respectively), were present. However, the intense $\mathrm{H}_{2} \mathrm{O}$ TPD peak at $355 \mathrm{~K}$ was absent and was replaced with a broader and weaker feature centered at about $380 \mathrm{~K}$. Additionally, the total amount of $\mathrm{H}_{2} \mathrm{O}$ adsorbed above $250 \mathrm{~K}$ decreased by $45 \%$ for the $\mathrm{O}_{2}$-presaturated surface. The adsorbed state of the $\mathrm{H}_{2} \mathrm{O}$ molecules desorbing in the $380 \mathrm{~K}$ TPD state is not known since HREELS experiments were not performed on this system. However, it is not unreasonable to assign the $380 \mathrm{~K}$ TPD state to recombinative desorption of hydroxyl groups given that the peak temperature is above that for the hydroxyl recombinative process observed on the clean surface (Figs. 10 and $11 \mathrm{~g}$ ). Kinetics for the $\mathrm{OH}$ recombination process in the $380 \mathrm{~K}$ TPD peak are clearly different from those for the $355 \mathrm{~K}$ TPD state on clean surface based on differences in peak shapes and temperatures.

The remaining TPD spectra shown in Fig. 11 probe, using water, the annealing temperature required to regenerate the clean surface after oxygen exposure. For each of these experiments, the $\mathrm{O}_{2}$-saturated surface was heated to progressively higher temperatures and then probed with $\mathrm{H}_{2} \mathrm{O}$ TPD. Preheating the $\mathrm{O}_{2}$-saturated surface up to $600 \mathrm{~K}$ did not significantly alter the subsequent $\mathrm{H}_{2} \mathrm{O}$ TPD (Fig. 11b), except that more surface sites were available for $\mathrm{H}_{2} \mathrm{O}$ adsorption in the TPD states above $240 \mathrm{~K}$ after desorption of $\mathrm{O}_{2}$ in the $285 \mathrm{~K}$ TPD state (Fig. 11a). After heating the $\mathrm{O}_{2}$-saturated surface to $690 \mathrm{~K}$, a small $\mathrm{H}_{2} \mathrm{O}$ TPD peak appears at $355 \mathrm{~K}$ (Fig. 11c). This $\mathrm{H}_{2} \mathrm{O}$ TPD peak increases in intensity and the $380 \mathrm{~K}$ $\mathrm{H}_{2} \mathrm{O}$ TPD state attenuates as the $\mathrm{O}_{2}$-saturated surface is preheated to progressively higher temperatures. However, the $\mathrm{H}_{2} \mathrm{O}$ TPD spectrum does not fully resemble the clean unstrained $\alpha-\mathrm{Cr}_{2} \mathrm{O}_{3}(001)$ surface $\mathrm{H}_{2} \mathrm{O}$ TPD spectrum even after heating to $860 \mathrm{~K}$ (Fig. 11f), indicating that some $\mathrm{Cr}^{3+}$ sites still remain 'capped' with $\mathrm{O}$ adatoms. Annealing at $950 \mathrm{~K}$ was sufficient to remove all atomic oxygen species from the unstrained $\alpha-\mathrm{Cr}_{2} \mathrm{O}_{3}(001)$ film. This is consistent with the findings of Dillmann et al. [19] discussed above. This series of TPD experiments clearly shows that atomic oxygen influences the adsorption properties of water on the $\alpha-\mathrm{Cr}_{2} \mathrm{O}_{3}(001)$ surface.

The $\mathrm{O}_{2}-\mathrm{H}_{2} \mathrm{O}$ experiment in Fig. 11 was repeated on the strained surface with similar results. However, a variation of this experiment is shown in Fig. 12 that probes the effect of high temperature ${ }^{18} \mathrm{O}_{2}$ treatment on the TPD of $\mathrm{H}_{2}{ }^{16} \mathrm{O}$ on the strained $\alpha-\mathrm{Cr}_{2} \mathrm{O}_{3}(001)$ surface. For this experiment, the surface was exposed to $150 \mathrm{~L}$ of ${ }^{18} \mathrm{O}_{2}$ at $700 \mathrm{~K}$ and cooled in ${ }^{18} \mathrm{O}_{2}$ to below $640 \mathrm{~K}$ before evacuating the chamber of ${ }^{18} \mathrm{O}_{2}$. This surface treatment presumably yields an $\alpha-\mathrm{Cr}_{2} \mathrm{O}_{3}(001)$ surface in which most, if not all, of the surface $\mathrm{Cr}^{3+}$ sites are capped with atomic ${ }^{18} \mathrm{O}$. Water TPD $(m / e=18)$ from this surface gives a peak at $295 \mathrm{~K}$ with a tailing feature at higher temperature (Fig. 12a). The total $\mathrm{H}_{2} \mathrm{O}$ TPD peak area above $250 \mathrm{~K}$ from

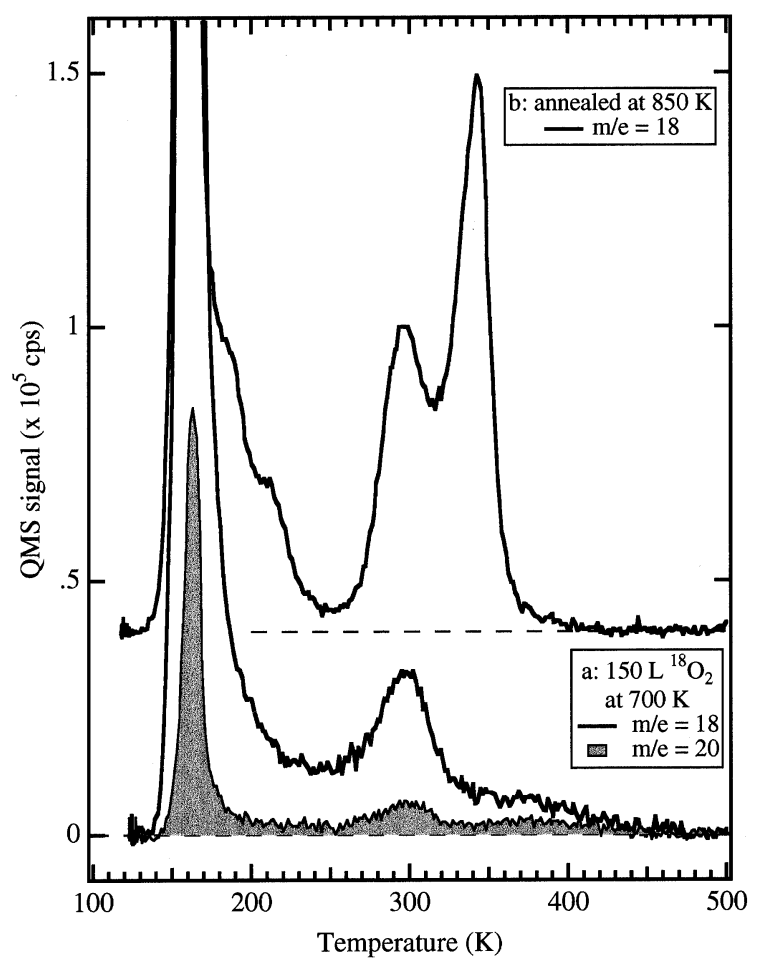

Fig. 12. $\mathrm{H}_{2}{ }^{16} \mathrm{O}(m / e=18)$ and $\mathrm{H}_{2}{ }^{18} \mathrm{O}(m / e=20)$ TPD spectra from about $5 \times 10^{15}$ molecules $/ \mathrm{cm}^{2} \mathrm{H}_{2}{ }^{16} \mathrm{O}$ exposure adsorbed on the strained $\alpha-\mathrm{Cr}_{2} \mathrm{O}_{3}(001)$ surface at $120 \mathrm{~K}$ after exposure of the surface to $150 \mathrm{~L}^{18} \mathrm{O}_{2}$ at $700 \mathrm{~K}$ (a). The $\mathrm{H}_{2}{ }^{16} \mathrm{O}(\mathrm{m} / \mathrm{e}=$ 18) TPD spectrum from the clean surface (b) is included for comparison. 
this surface was nearly $50 \%$ less than that observed from the clean surface (Fig. 12b). (For the purposes of this comparison, the $m / e=18$ and 20 signals in Fig. 12a were combined.) This $50 \%$ decrease in the $\alpha-\mathrm{Cr}_{2} \mathrm{O}_{3}(001)$ surface's ability to bind water arises primarily from the absence of the high temperature $\mathrm{H}_{2} \mathrm{O}$ TPD state (at $345 \mathrm{~K}$ ) attributed to $\mathrm{OH}$ recombination on the clean surface, whereas the majority of the observed water desorption is found at the same temperature as the molecular desorption state on the clean surface (at $295 \mathrm{~K}$ ). It therefore seems logical to conclude that oxygen adatoms on the $\mathrm{Cr}^{3+}$ sites block the dissociation of water but do not block $\mathrm{H}_{2} \mathrm{O}$ adsorption into the molecular state. The $m / e=20 \mathrm{TPD}$ trace in Fig. 12a shows that little or no oxygen atom scrambling occurs between the coadsorbed $\mathrm{H}_{2}{ }^{16} \mathrm{O}$ and ${ }^{18} \mathrm{O}$ atoms, which is further evidence for the absence of water dissociation on the oxygen capped $\mathrm{Cr}^{3+}$ sites. (The $m / e=20$ signal tracks the $m / e=18$ signal, indicating that it arises primarily from exchange in the mass spectrometer, which unavoidably is exposed to ${ }^{18} \mathrm{O}_{2}$ during the surface oxidation process.) There is, however, a slight enhancement in the relative amount of $\mathrm{H}_{2}{ }^{18} \mathrm{O}$ desorbing above $330 \mathrm{~K}$, suggesting that the high temperature tail is due to recombinative desorption of water. Based on these findings, the $\mathrm{Cr}^{3+}$ cation sites appear to bind both a water molecule and an oxygen adatom, but proton transfer between the water and the oxygen atom to form two geminal dihydroxyl species does not occur (under UHV conditions). Instead, oxygen can be viewed as a poison of $\mathrm{H}_{2} \mathrm{O}$ dissociation sites on $\alpha-\mathrm{Cr}_{2} \mathrm{O}_{3}(001)$. This is the complete opposite of what Epling et al. observed for the interaction of oxygen adatoms and water molecules on $\mathrm{TiO}_{2}(110)$ [46]. This difference between the coadsorption behavior of water and atomic oxygen on $\alpha-\mathrm{Cr}_{2} \mathrm{O}_{3}(001)$ and on $\mathrm{TiO}_{2}(110)$ suggests that water dissociation is very sensitive to the nature of the oxide surface.

\section{Conclusions}

The $\alpha-\mathrm{Cr}_{2} \mathrm{O}_{3}(001)$ surface is very active for dissociation of water under UHV conditions.
Water adsorption results in formation of paired $\mathrm{OH}$ groups comprised of a terminal $\mathrm{OH}$ group (containing the water molecule's oxygen atom) and a bridging $\mathrm{OH}$ group (containing a surface oxygen atom) in which the proton of the latter is hydrogenbonded to the oxygen of the former. The hydrogenbonding interaction is unusually strong, resulting in a very low $v(\mathrm{OH})$ stretch at $2885 \mathrm{~cm}^{-1}$ for the bridging $\mathrm{OH}$ group. These paired hydroxyls recombine with first-order desorption kinetics to evolve water in TPD at $345 \mathrm{~K}$. The three-coordinate $\mathrm{Cr}^{3+}$ cation that is the site for the terminal $\mathrm{OH}$ group also has the capacity to bind another water molecule in a non-dissociative form. To our knowledge, this is the first observation of multiple water species bound to a single cation site on a single crystal oxide surface. Preadsorbed oxygen, however, blocks the dissociative channel, but does not block the molecular adsorption site.

\section{Acknowledgements}

We thank Craig L. Perkins for assistance in mounting the substrates in the HREELS/TPD chamber. This work was supported by the US Department of Energy, Office of Basic Energy Sciences, Division of Materials Sciences. Pacific Northwest National Laboratory (PNNL) is a multiprogram national laboratory operated for the US Department of Energy by Battelle Memorial Institute under Contract DE-AC06-76RLO 1830. The research reported here was performed in the William R. Wiley Environmental Molecular Science Laboratory, a Department of Energy user facility at PNNL funded by the US Department of Energy, Office of Biological and Environmental Research.

\section{References}

[1] T. Bredow, Surf. Sci. 401 (1998) 82.

[2] C. Rehbein, N.M. Harrison, A. Wander, Phys. Rev. B 54 (1996) 14066.

[3] F. Rohr, M. Baeumer, H.-J. Freund, J.A. Mejias, V. Staemmler, S. Mueller, L. Hammer, K. Heinz, Surf. Sci. 372 (1997) L291.

[4] S. Thevuthasan, Y.J. Kim, S.I. Yi, S.A. Chambers, 
J. Morais, R. Denecke, C.S. Fadley, P. Liu, T. Kendelewicz, G.E. Brown Jr., Surf. Sci. 425 (1999) 276.

[5] E. Wasserman, J.R. Rustad, A.R. Felmy, B.P. Hay, J.W. Halley, Surf. Sci. 385 (1997) 217.

[6] V.E. Puchin, J.D. Gale, A.L. Shluger, E.A. Kotomin, J. Guenster, M. Brause, V. Kempter, Surf. Sci. 370 (1997) 190

[7] S. Blonski, S.H. Garofalini, Surf. Sci. 295 (1993) 263.

[8] T.J. Godin, J.P. LaFemina, Phys. Rev. B 49 (1994) 7691.

[9] K.C. Hass, W.F. Schneider, A. Curioni, W. Andreoni, Science 282 (1998) 265.

[10] I. Manassidis, A. De Vita, M.J. Gillan, Surf. Sci. 285 (1993) L517.

[11] C. Rehbein, F. Michel, N.M. Harrison, A. Wander, Surf. Rev. Lett. 5 (1998) 337.

[12] T. Gloege, H.L. Meyerheim, W. Moritz, D. Wolf, Surf. Sci. 441 (1999) L917.

[13] D. Cappus, C. Xu, D. Ehrlich, B. Dillmann, C.A. Ventrice Jr., K. Al Shamery, H. Kuhlenbeck, H.-J. Freund, Chem. Phys. 177 (1993) 533.

[14] S.A. Chambers, Y. Liang, Phys. Rev. B (2000) in press.

[15] S.A. Chambers, unpublished results.

[16] C. Xu, M. Hassel, H. Kuhlenbeck, H.-J. Freund, Surf. Sci. 258 (1991) 23.

[17] M. Bender, D. Ehrlich, I.N. Yakovkin, F. Rohr, M. Bauemer, H. Kuhlenbeck, H.-J. Freund, V. Staemmler, J. Phys. C: Condens. Matter 7 (1995) 5289.

[18] Q. Guo, L. Gui, P.J. Möller, K. Binau, Appl. Surf. Sci. 92 (1996) 513

[19] B. Dillmann, F. Rohr, O. Seiferth, G. Klivenyi, M. Bender, K. Homann, I.N. Yakovkin, D. Ehrlich, M. Bäumer, H. Kuhlenbeck, H.-J. Freund, Faraday Discuss. 105 (1996) 295.

[20] I. Hemmerich, F. Rohr, O. Seiferth, B. Dillmann, H.-J. Freund, Z. Phys. Chem. 202 (1997) 31.

[21] J.A. Mejias, V. Staemmler, H.-J. Freund, J. Phys. C: Condens. Matter 11 (1999) 7881.

[22] M.A. Henderson, Surf. Sci. 355 (1996) 151.

[23] Y. Fukuda, A. Ignatiev, Solid State Commun. 41 (1982) 597.

[24] M.A. Henderson, S.A. Joyce, J.R. Rustad, Surf. Sci. 417 (1998) 66.
[25] F.E. Livingston, J.A. Smith, S.M. George, Surf. Sci. 423 (1999) 145.

[26] M.A. Henderson, Langmuir 12 (1996) 5093

[27] C.A. Ventrice Jr., D. Ehrlich, E.L. Garfunkel, B. Dillmann, D. Heskett, H.J. Freund, Phys. Rev. B: Condens. Matter 46 (1992) 12892.

[28] H. Kuhlenbeck, C. Xu, B. Dillmann, M. Hassel, B. Adam, D. Ehrlich, S. Wohlrab, H.-J. Freund, U.A. Ditzinger, H. Neddermeyer, M. Neuber, M. Neumann, Ber. Bunsenges. Phys. Chem. 96 (1992) 15.

[29] D.R. Renneke, D.W. Lynch, Phys. Rev. A 138 (1965) 530.

[30] C.J. Serna, J.L. Rendon, J.E. Iglesias, Spectrochim. Acta 38A (1982) 797.

[31] K. Wolter, D. Scarano, J. Fritsch, H. Kuhlnebeck, U. Schröder, A. Zecchina, H.-J. Freund, discussion comments, Discuss. Faraday Soc 114 (1999) 90 and personal communication.

[32] N.M. Harrison, X.-G. Wang, J. Muscat, M. Scheffler, Faraday Discuss. 114 (1999) 305.

[33] K.W. Wulser, M.A. Langell, Phys. Rev. B 48 (1993) 9006.

[34] A.A. Davydov, Infrared Spectroscopy of Adsorbed Species on the Surface of Transition Metal Oxides, Wiley, New York, 1984.

[35] A. Zecchina, S. Coluccia, E. Guglielminotti, G. Ghiotti, J. Phys. Chem. 75 (1971) 2774.

[36] S. Kittaka, T. Sasaki, N. Fukuhara, H. Kato, Surf. Sci. 282 (1993) 255.

[37] G. Busca, V. Lorenzelli, G. Ramis, R.J. Willey, Langmuir 9 (1993) 1492.

[38] O. Seiferth, K. Wolter, B. Dillmann, G. Klivenyi, H.-J. Freund, D. Scarano, A. Zecchina, Surf. Sci. 421 (1999) 176.

[39] M.A. Henderson, unpublished work.

[40] X. Li, V.E. Henrich, Surf. Sci. Spectra 5 (1998) 165.

[41] P.A. Thiel, T.E. Madey, Surf. Sci. Rep. 7 (1987) 211

[42] S. Tanuma, C.J. Powell, D.R. Penn, Surf. Interface Anal. 11 (1988) 577.

[43] A. Novak, Struct. Bond. (Berlin) 18 (1974) 177.

[44] R.C. Weast (Ed.), Handbook of Chemistry and Physics, fifty seventh ed., CRC Press, Cleveland, OH, 1977.

[45] M.A. Henderson, W.S. Epling, C.L. Perkins, C.H.F. Peden, U. Diebold, J. Phys. Chem. B 103 (1999) 5328.

[46] W.S. Epling, C.H.F. Peden, M.A. Henderson, U. Diebold, Surf. Sci. 412/413 (1998) 333. 